\title{
Influence of rainfall on the deformation and stability of a slope in overconsolidated clays: a case study
}

\author{
E. E. Alonso • A. Gens • C. H. Delahaye
}

\begin{abstract}
The behaviour of an instrumented unstable slope in a profile of weathered overconsolidated clay has been analysed. Available field investigation data and laboratory tests were integrated in a coupled hydromechanical model of the slope. Particular attention was given to the unsaturated soil conditions above the water table and to the influence of the rainfall record. Recorded pore-water pressures helped to identify the hydrogeological conditions of the slope. The coupled model was used to compute slope deformations and the variation of safety with time. Actual rainfall records were also integrated into the analysis. Comparison of measurements and calculations illustrate the nature of the slope instability and the complex relationships between mechanical and hydraulic factors.
\end{abstract}

Résumé Une pente instable dans un profil d'argile altérée sur-consolidée a été instrumentée et son comportement a été analysé. Des données disponibles obtenues lors d'étude sur le terrain et des essais en laboratoire ont été intégrés dans un modèle couplé hydromécanique de la pente. Une attention particulière a été portée aux conditions du sol non saturé au-dessus de la nappe et à l'influence de la succession de pluies. Les pressions enregistrées de l'eau dans les pores ont permis d'identifier les conditions hydrogéologiques de la pente. Le modèle couplé a été utilisé pour calculer les déformations de la pente et la variation de sécurité au cours du temps. Les enregistrement de pluies réelles ont été également intégrés à l'analyse. La comparaison des mesures aux calculs illustre la nature de l'instabilité de la pente et les

Received: 13 September 2002 / Accepted: 29 November 2002 Published online: 17 January 2003

(C) Springer-Verlag 2003

E. E. Alonso (- A ) Aens

Department of Geotechnical Engineering and Geosciences,

Universidad Politécnica de Catalunya,

C/ Jordi Girona 1-3, 08034 Barcelona, Spain

e-mail: eduardo.alonso@upc.es

Tel.: +34-93-4016866, Fax: +34-93-4017251

C. H. Delahaye

Universidad de San Juan, Argentina relations complexes entre les facteurs mécaniques et hydrauliques.

Resumen Se ha analizado el comportamiento de una ladera instable que fue instrumentada en un perfil de arcillas meteorizadas sobreconsolidadas. Se ha integrado los datos disponibles de investigaciones de campo y ensayos de laboratorio en un modelo hidromecánico acoplado de la ladera, prestando una atención especial a las condiciones del suelo no saturado por encima del nivel freático y a la influencia de los registros de lluvia. Los registros de presión del agua han ayudado a la identificación de las condiciones hidrogeológicas de la ladera. El modelo acoplado ha servido para calcular las deformaciones de la ladera y el cambio de la seguridad con el tiempo, integrando también los datos reales de lluvia. La comparación entre valores medidos y calculados ilustra la naturaleza de la inestabilidad de la ladera y las complejas relaciones que se establecen entre factores mecánicos e hidráulicos.

Keywords Overconsolidated clays - Slope instability · Expansion · Flow $\cdot$ Unsaturated soil $\cdot$ Suction $\cdot$ Safety factor

\section{Introduction}

In December 1982 a large flowslide in overconsolidated clays caused the destruction of three suburbs of the city of Ancona in eastern Italy. The area, which is located in the southwest region of the city, has been, in the years following the disaster, under close observation as a potential slide area. Soil profiles were established and the pattern of slope movements and water pressure fluctuations were established (Franchini and Callari 1988; Baldelli et al. 1992). In 1991, a project financed by the European Programme on Climatology and Natural Hazards (EPOCH) was awarded to several European institutions with the purpose of analysing the stability of slopes in overconsolidated clays in the context of Mediterranean climates. A slope close to the sliding area, which affected Ancona in 1982, herein referred to as the Villa Blasi slope, was selected as an experimental site to perform a number of interrelated studies. Ten boreholes were drilled along the slope, samples were taken for labo- 
ratory testing, and inclinometers and electric piezometers provided field data in the period October 1992-October 1993. Rainfall in the area was also recorded. All these activities were described in a project final report (Baldelli et al. 1994). It was the responsibility of the authors of this paper to identify the characteristics of the unsaturated upper levels of the slope, perform controlled suction tests, and construct a model of the response of the slope to rainfall. Additional analyses performed after the EPOCH project was formally finalised have led to an improved understanding of the mechanisms of slope motion and its relationship with rainfall and the hydraulic characteristics of the clay strata. This paper provides an account of all this work. Geological and geotechnical field data, as well as hydraulic and mechanical properties measured in samples have been integrated into a coupled hydromechanical model of the slope. The computed evolution of the slope, subjected to the rainfall action, was compared with field measurements. The question of safety has also been addressed, and the evolution of the safety factor and its relationship with the rainfall record and the hydraulic properties of the soil was analysed. This work, which extended over a number of year's, has provided a better insight into the role of suction, environmental actions and soil heterogeneity on slope stability.

This case examines the stability of a slope in overcon-

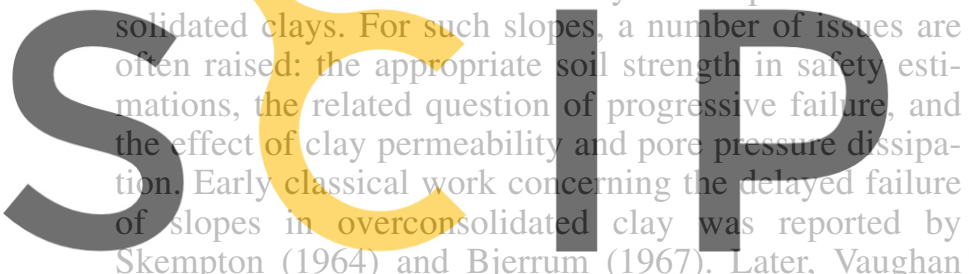
and Walbancke (1973) realised that pore-water dissipa-

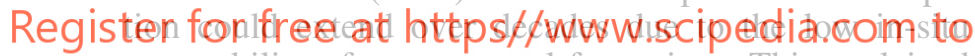
permeability of some natural formations. This explained delayed failures associated with cuts and excavations. The persistence of transient water changes is also observed when negative pressures are induced in the slope (Bromhead 2000).

Undisturbed overconsolidated clays are brittle materials with marked peak strengths. Progressive failure mechanisms, well documented in Cooper (1996), lead to a reduction of the available in-situ strength. The important practical problem of selecting the design strength is largely unresolved and it has been addressed by several authors (Chandler 1984; Cancelli and Chinaplia 1993; D'Elia et al. 1998; Leroueil 2001). A review of current constitutive models to describe the mechanical behaviour of overconsolidated clays and soft clayey rocks is given in Kavvadas (2000). Advances in modelling progressive failure are reported in Potts et al. (1997).

In reactivated slides the relevant in-situ strength is close to residual values. A discussion of factors affecting residual strength and the role of discontinuities (bedding planes, in particular) is given in Alonso (2000). The reduction of friction induced by leaching and other physico-chemical actions has been raised in this reference and in Frydman et al. (1996) and DiMaio (1996).
A significant feature of the analysis presented is the use of a coupled hydromechanical model which may relate slope displacements and safety assessments with water-pressure evolution, both for positive and negative (suction) values. This is believed to be a common situation in nature.

The purpose of this paper is to analyse the conditions leading to the instability of the Villa Blasi slope. Attention will be focused on rainfall and on the role played by the heterogeneous distribution of soil permeability and strength. These factors are believed to control the stability of the slope and its evolution in time.

\section{Geomechanical Characteristics of the Slope}

The slope is located in clay sediments of Plio-Pleistocene age. The undisturbed, jointed base material is covered by eluvial-colluvial deposits which reach thicknesses of $10 \mathrm{~m}$. A longitudinal profile of the slope is shown in Fig. 1, where the location and depth of the borings performed in 1992 are also indicated. Figure 2 shows the detailed boring record of borehole $\mathrm{C}$. The transition between the upper, weathered brown layers and the grey clay substratum was easily identified. Three layers were identified when all the field data were analysed: a Plio-

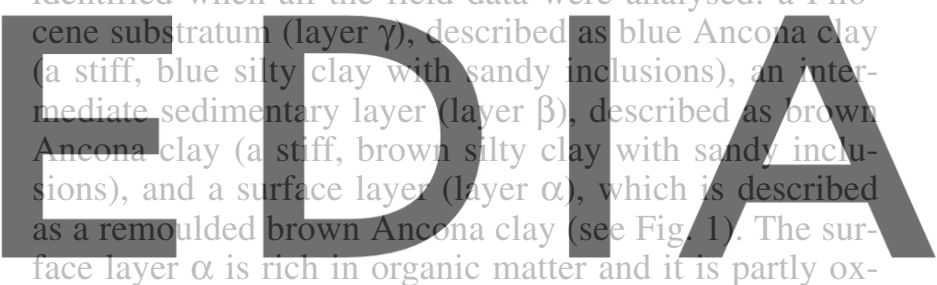

download the version without the watermark

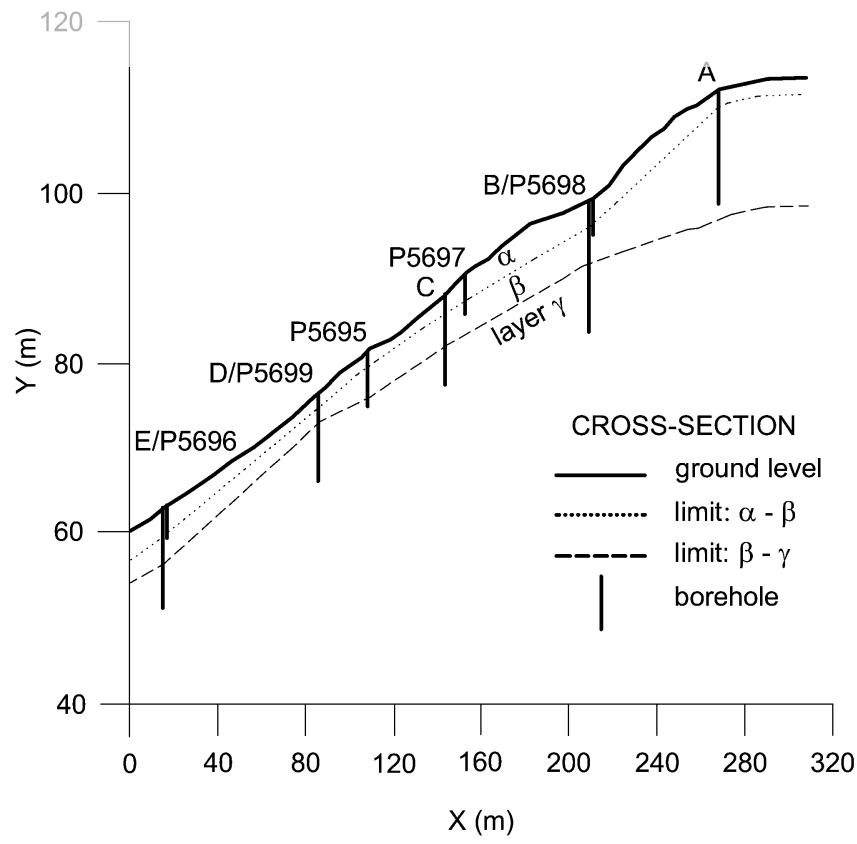

Fig. 1 Slope profile showing the position of boreholes and the stratigraphic sequence 
BOREHOLE C

\begin{tabular}{c|c|l|l|l|}
$\begin{array}{c}\text { Depth } \\
\text { (m) }\end{array}$ & \multicolumn{1}{c|}{ Description } & $\begin{array}{c}\text { Undisturbed } \\
\text { samples }\end{array}$ & $\begin{array}{c}\text { Pocket } \\
\text { penetrometer } \\
\left(\mathrm{kg} / \mathrm{cm}^{2}\right)\end{array}$ \\
\hline
\end{tabular}

Fig. 2 Stratigraphy of borehøle C. Sampling and physical characteristics

idised. Soil movements take place in the upper brown

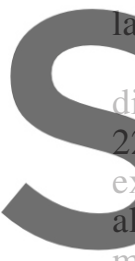

ayers $(\alpha, \beta)$ but not in the blue

Soil mineralogy was esse

different layers. Carbonates

$22 \%$ of the total mineral con

tent

present. The dominant

montmorillonite, illite, chlorite and dolomite $(61,73,8$ and $7 \%$ of the clay fraction, on average).

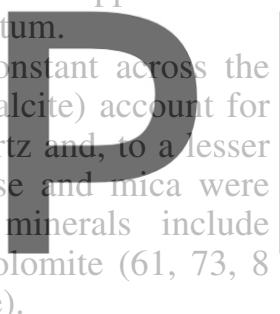

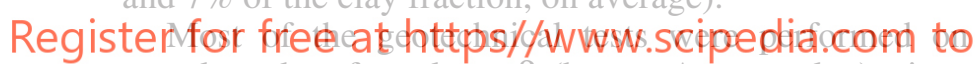
samples taken from layer $\beta$ (brown Ancona clay), since the slope deformations were concentrated in that layer.

Soil in layers $\beta$ and $\gamma$ are classified as inorganic clays and silts of high plasticity $\left(\mathrm{CH}\right.$ and $\mathrm{MH} ; w_{L}=52-64 \%$; $\mathrm{PI}=25-34 \%$; clay fraction $=40-55 \%$; a small proportion of sand sizes $=1-8 \%$ ). Natural water content in layers $\beta$ and $\gamma$ was close to the plastic limit and varied in the range $21-32 \%$. The specific particle weight was in the range $\gamma_{s}=27.2-27.8 \mathrm{kN} / \mathrm{m}^{3}$. High overconsolidation vertical stresses (2-3 MPa for layer $\beta$, and 3-4 MPa for layer $\gamma$ ) were measured in oedometer tests.

Clay strength was investigated by drained and undrained, isotropically consolidated samples of intact as well as reconstituted specimens. Figure 3 shows the deviatoric stresses (Fig. 3a) and recorded volume change (Fig. 3b) measured in triaxial tests conducted on isotropically consolidated, undisturbed samples taken from the $\beta$ horizon (Baldelli et al. 1994). Specimens failed in a brittle mode along a well-defined plane. A significant brittleness and dilatant behaviour at peak and post-peak conditions was measured. Stiffness for an axial strain of $1 \%$ increased from 14 to $29 \mathrm{MPa}$ when the confining stress increased from 50 to $250 \mathrm{kPa}$ (the average estimated confining stress for the $\beta$ layer is around $100 \mathrm{kPa}$ ).
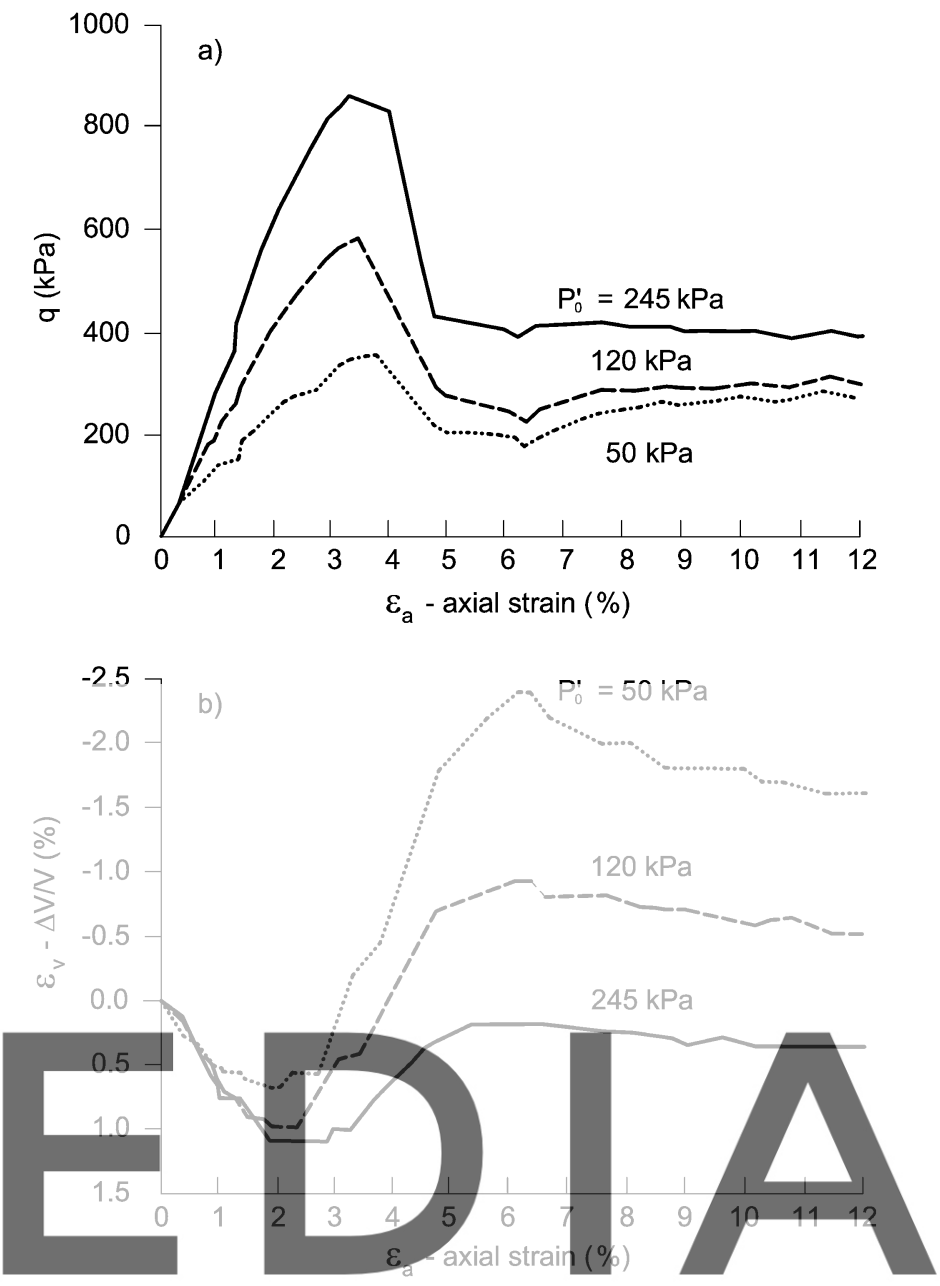

Fig. 3a, b Isotropically consolidated drained triaxial compression downtoad the version without the watermark

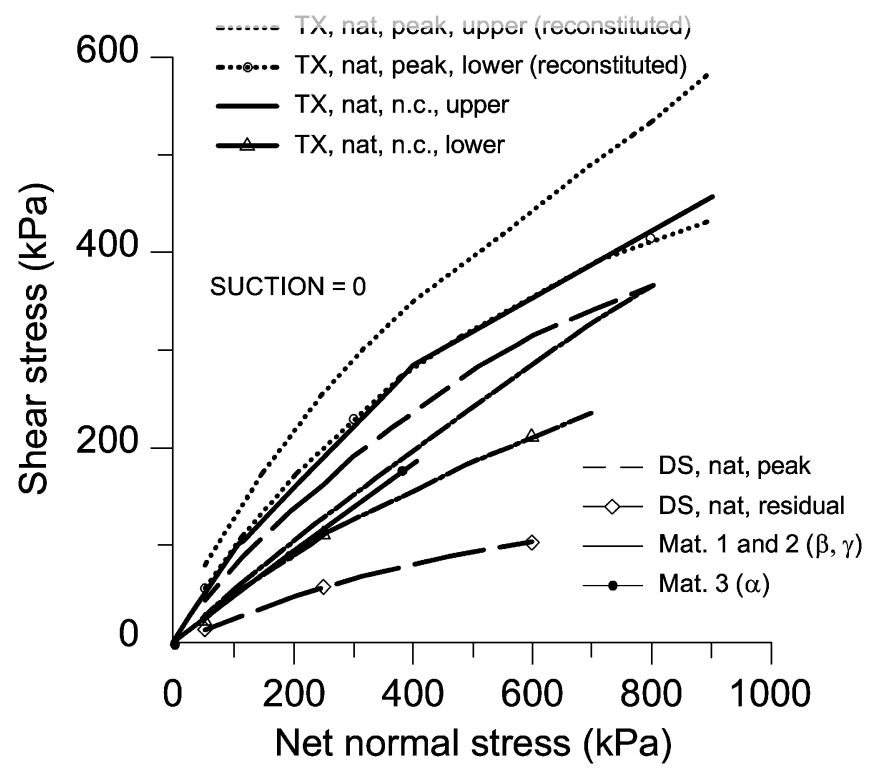

Fig. 4 Strength envelopes for natural and reconstituted samples. Also shown are the strength laws adopted for layers $\alpha, \beta$ and $\gamma$. $T X$ Triaxial tests, $D S$ direct shear tests 


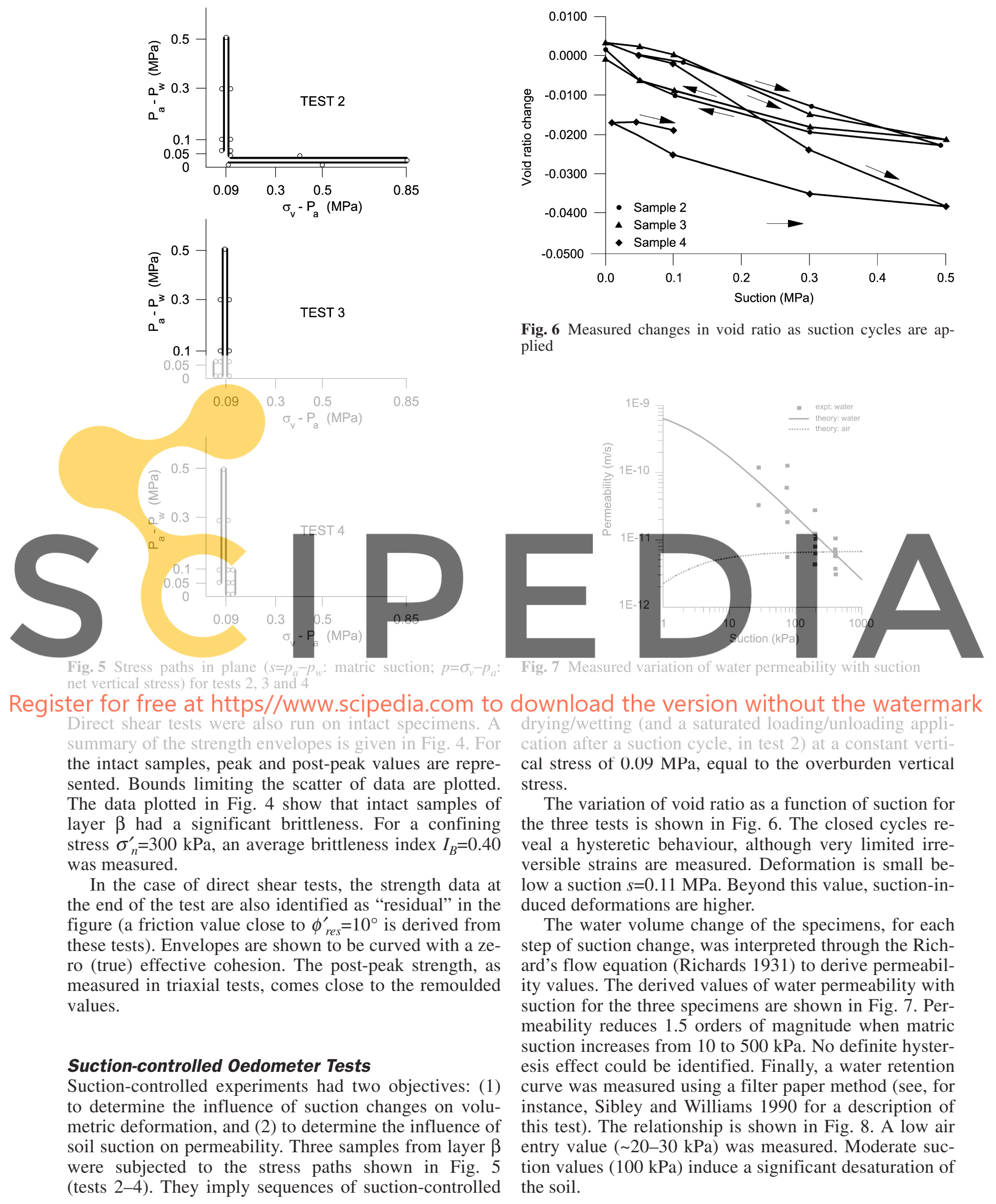




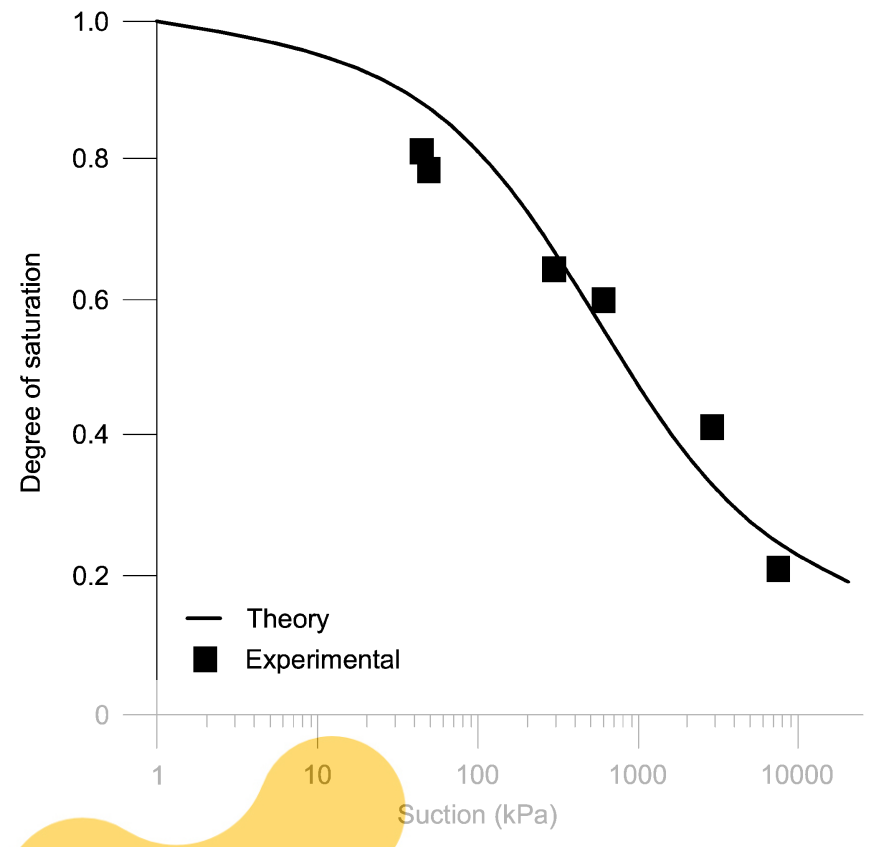

Fig. 8 Water retention curve obtained by means of the filter paper method

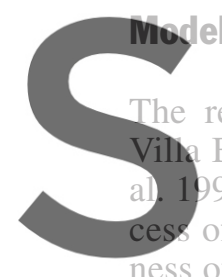

elling the Villa Blasi Slope

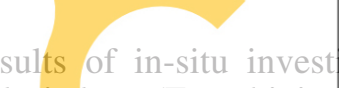

Blasi slope (Franchini a

992,1994 ) have confirmed

of the slope is essential

hess of 2-3 m. The measured deformations are attributed to changes in suction and effective stresses as the water

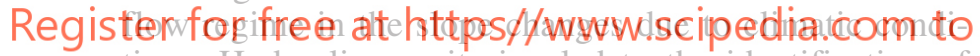
tions. Hydraulic monitoring led to the identification of two different hydraulic regimes within the slope, defined as follows.

1. A deep flow regime, which is characterised by a phreatic level nearly constant in both wet and dry seasons. The phreatic surface was detected at depths which vary in the range 4-12 m. A flow regime approximately parallel to the slope surface is consistent with observations.
2. A surficial flow regime, directly controlled by rainfall. Positive and negative pore-water pressures were measured during the year within the upper few metres.

Given this background, it was decided to study the response of the slope through a finite-element model which could handle flow under saturated/unsaturated conditions, and the mechanical interaction associated with changes in soil suction. The authors have developed in the past two decades a series of models of increasing complexity to deal with these coupled problems (Lloret and Alonso 1980; Alonso et al. 1988; Olivella et al. 1994, 1996). The general approach is to solve the continuity equations for air and flow coupled with mechanical equilibrium conditions. Improved understanding of the mechanical and hydraulic behaviour of the unsaturated soils has resulted in updated constitutive equations, which explain the evolution of the computational tools described in the quoted references.

The model used to describe the Villa Blasi slope is described in the Appendix. It may be described as a model of medium complexity as far as the mechanical characterisation of the soil and the effect of suction is concerned. In fact, it was realised that the success of the modelling exercise was closely related to a reasonable

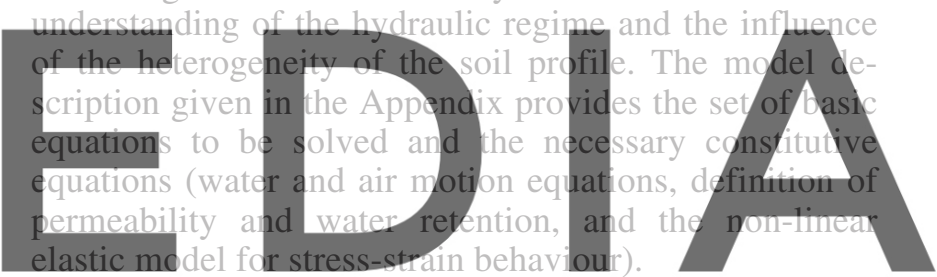

Reference should be made to the Appendix to interpret the set of constitutive parameters used in the analy downioad the version without the waterbe-ark low.

The discretisation of the slope is shown in Fig. 9. The area covered by the F.E. mesh extends $308.5 \mathrm{~m}$ horizontally. The highest and lower levels of the slope surface are 113 and $60 \mathrm{~m}$ respectively. The lower horizontal boundary is located $20 \mathrm{~m}$ below the lowest point of the slope surface. Three materials are distinguished. The interfaces follow the actual positions identified in borings. In total the mesh has 648 four-noded, linear quadrilateral

Fig. 9 Finite-element mesh

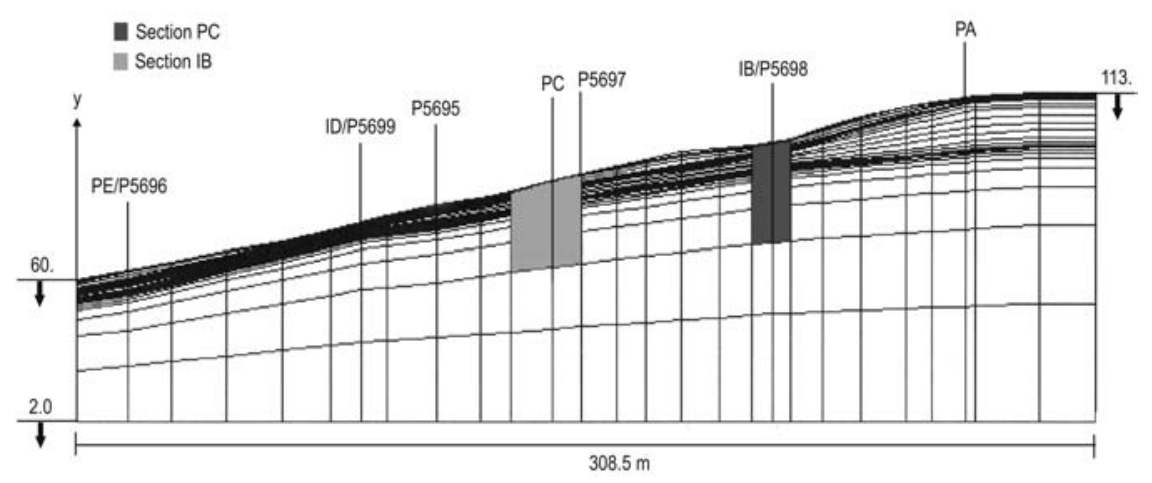


elements. The mesh is denser at the free surface and in the vicinity of material interfaces where high flow gradients are expected. Also indicated in Fig. 9 are the positions of instrumented boreholes. The letters $\mathrm{P}$ and I, at the beginning of each borehole identification number, indicate the presence of piezometers and inclinometers respectively. Two "thick columns" (PC and IB) around the position of boreholes $\mathrm{C}$ and $\mathrm{B}$ are also indicated. Some modelling details, presented below, refer to these two zones.

The computations have been organised in three phases: (1) definition of equilibrium conditions, (2) analysis of rainfall infiltration, and (3) deformation analysis and evaluation of safety factors. They are further described below.

1. Equilibrium conditions. The aim of this phase is to get an equilibrated state of stress within the slope and a reference water pressure distribution consistent with piezometric data on 1 October 1992. These equilibrium conditions are the initial conditions for phase 2 . This date was also the initiation for displacement analysis. In fact, the period of observations considered in the paper extends from 1 October 1992 to 31 October 1993. During this period, observed changes in piezometer readings and deformations in inclino-

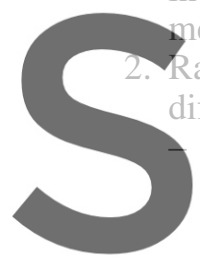
meters were associated with

\section{Rainfall infiltration. Two} different boundary conditi Controlled infiltration. rainfall, $I$, is smaller tha O., which can infiltrate through Then, the inflow is controlled by the rain intensity. A prescribed flow boundary is adopted: $Q_{i}=I$.

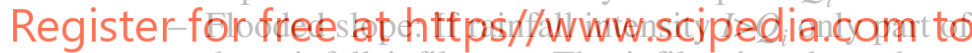
the rainfall infiltrates. The infiltration depends on the computed permeability and degree of saturation of the slope surface. A boundary condition for a flooded slope $\left(s=p_{a}-p_{w}=0\right)$ was applied at the surface of the slope.

The following methodology was applied to the available rainfall records (which correspond to the nearby village of Posatora): average uniform monthly flow rates were computed. These flows were imposed as flow boundary conditions at the slope surface. If a positive pore-water pressure $\left(p_{w}>0\right)$ was computed at the slope surface (which is an indication that the rainfall rate was larger than the infiltration capacity of the soil), the boundary condition was changed to $s=0$.

3. Deformation analysis and evaluation of safety factors. The model provided time records of slope deformations in parallel with the flow analysis. Local safety factors were determined by comparing, at some selected points within the slope, available shear strength and existing shear stress. Details of the procedure are given below.

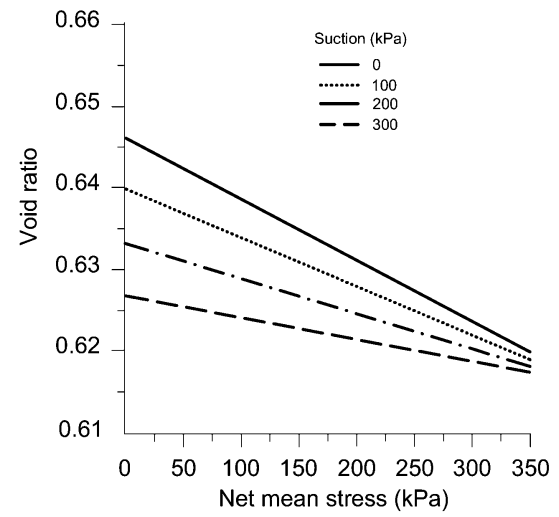

Fig. 10 State surface for void ratio. Sections along constant suction values
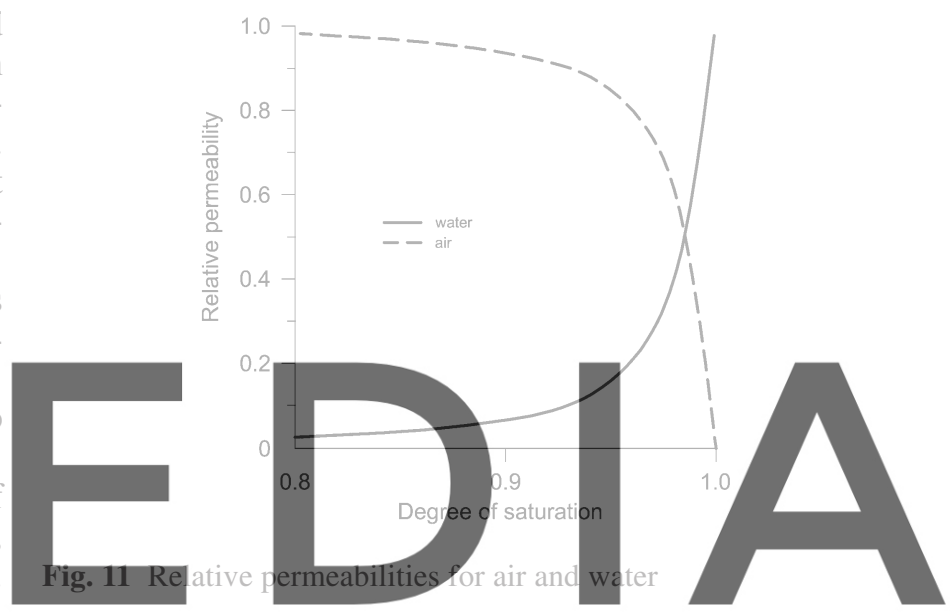

deaillowadethe version without the watermark Soil parameters were derived from laboratory tests. Most of the specimens tested were taken from layer $\beta$ and consequently the derived parameters correspond to that layer. Parameters for the upper and lower layers were based on the basic set for layer $\beta$. In fact, the state surface for void ratio, the water retention curve, and the relative permeability were accepted to be represented by common laws for the three layers. Layer differences were assigned to saturated (or intrinsic) permeabilities and to shear-strength laws. Soil parameters are shown in Table 1.

The state surface for void ratio was approximated on the basis of the suction-controlled oedometer tests. The analytical expression suggested by Lloret and Alonso (1985) was fitted to measured values (Fig. 10). The analytical expression given by Bourgeois (1986) was used for the water retention curve (Fig. 8). The variation of water permeability with suction was derived from measured values (Fig. 7). Figure 11 shows the resulting variation of water relative permeability with degree of saturation. A symmetrical relationship was adopted for air relative permeability (Fig. 11). Analytical expressions are given in the Appendix.

The shear-strength data (Fig. 4) were approximated with piece-wise linear approximations for increasing 


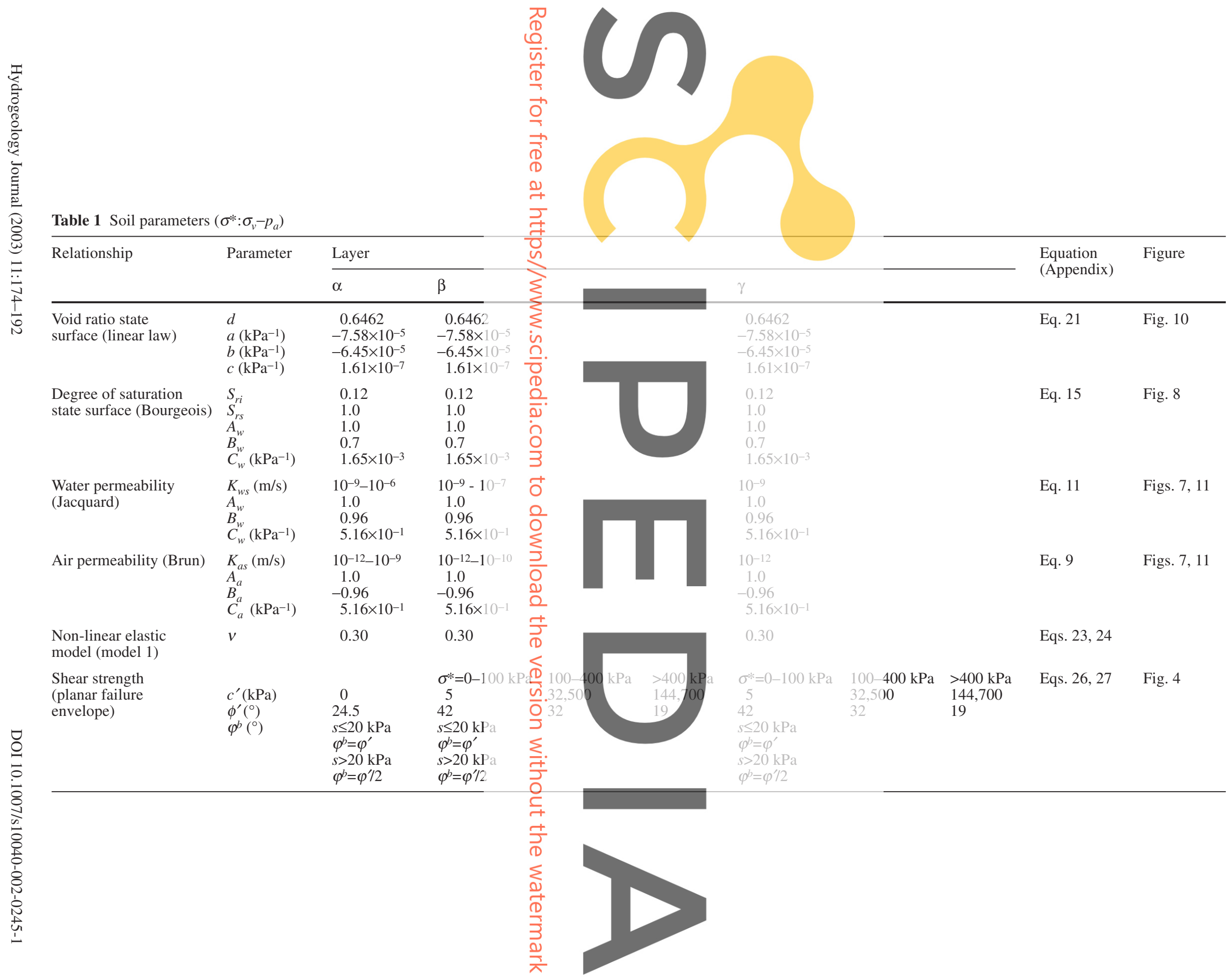




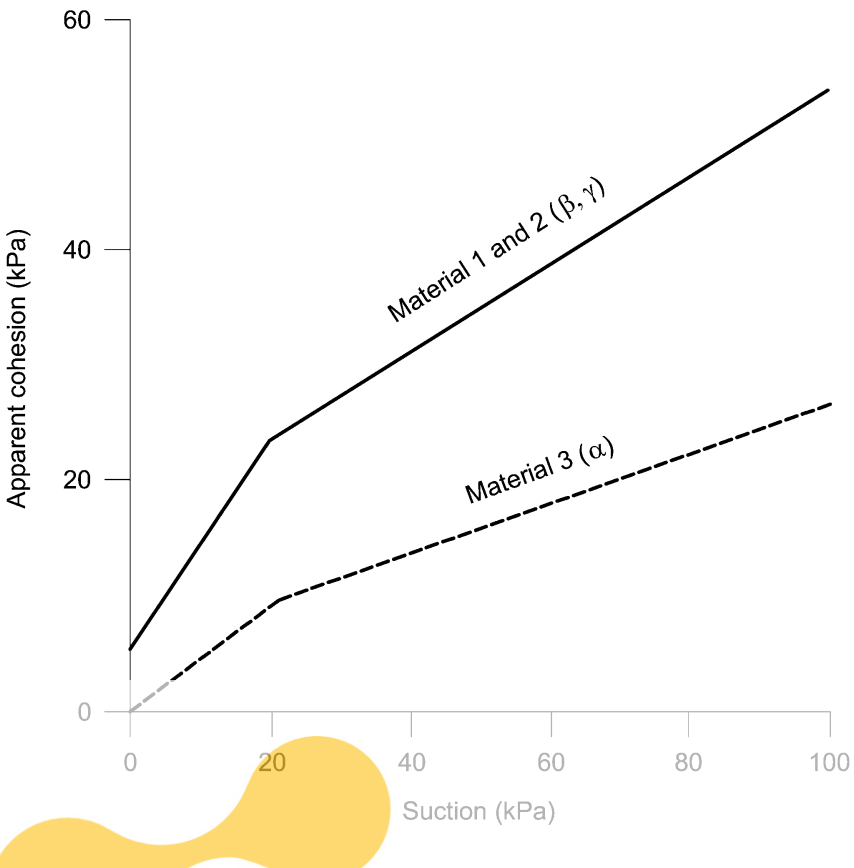

Fig. 12 Variation of apparent cohesion with suction

confining stresses (see data for layers $\beta$ and $\gamma$ in Ta-

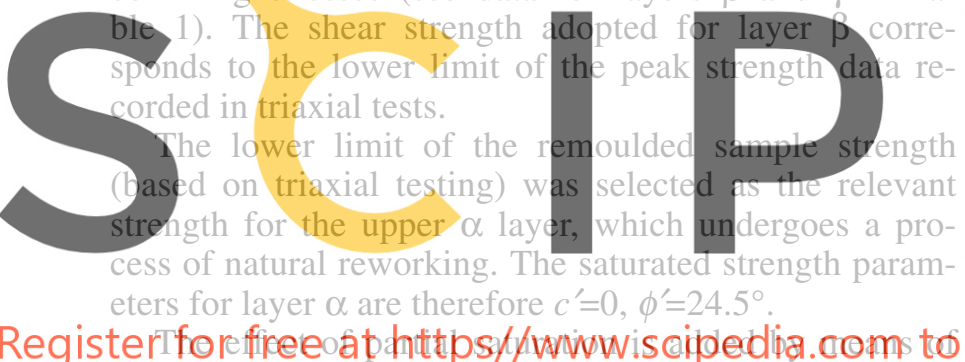

the apparent cohesion intercept, $c$, which increases with suction (Fig. 12). To ensure consistency with the saturated strength expression, the variation of $c$ with $s$ (angle $\left.\varphi^{b}\right)$ was made equal to $\varphi^{\prime}$ for suctions in the vicinity of zero $(s \leq 20 \mathrm{kPa})$. At higher suctions, a value of $\varphi^{b}=\varphi^{\prime} / 2$ was adopted. This choice is an approximation based on published experimental results on the influence of suction on shear strength (Fredlund and Rahardjo 1993).

\section{Equilibrium Conditions of the Slope}

Boundary conditions for the discretised geometry of the slope are established as marked in Fig. 13 for water flow, air flow and mechanical conditions. The water table is a surface of zero air and water pressure. Water pressures as well as air pressures at the lateral boundaries increase linearly below the phreatic surface, since suction is maintained at zero under saturated conditions. The upper and lower boundaries for water flow had a zero prescribed flow. Air flow was also nil at the lower boundary, and the atmospheric condition (zero air pressure) was applied at the upper boundary. Two lower fixed points and zero normal displacements at the lateral and (a) FLOW : WATER
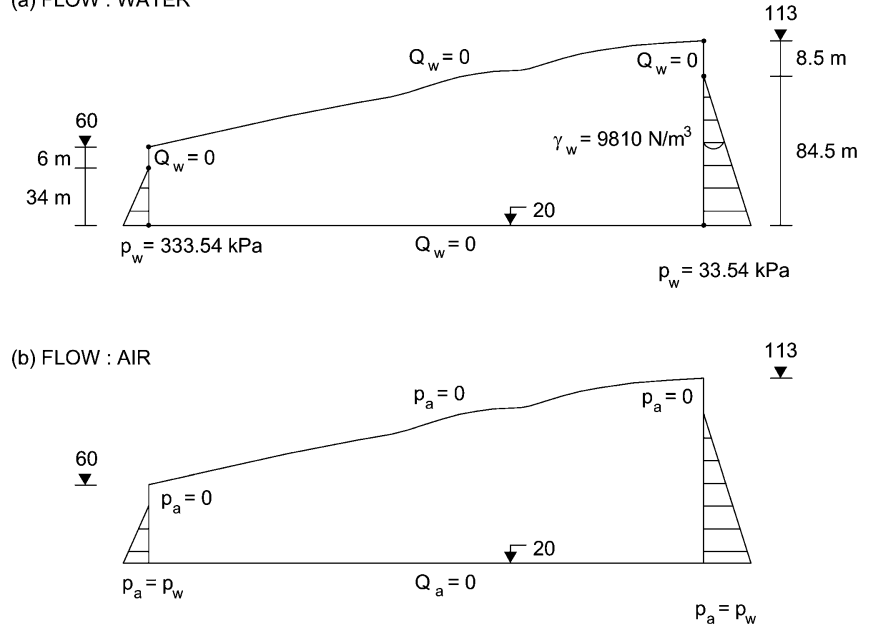

(c) MECHANICAL

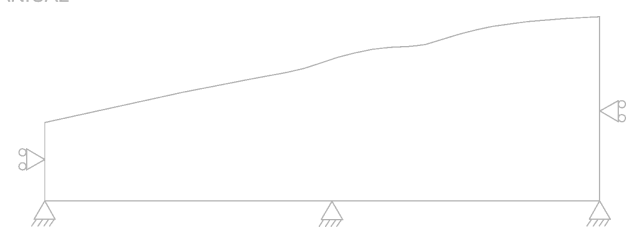

Fig. 13a-c Boundary conditions for a flow of water, b flow of air,

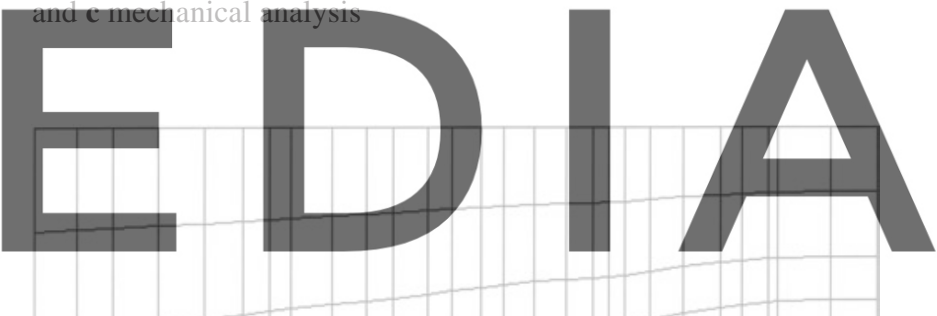

download the version without the watermark

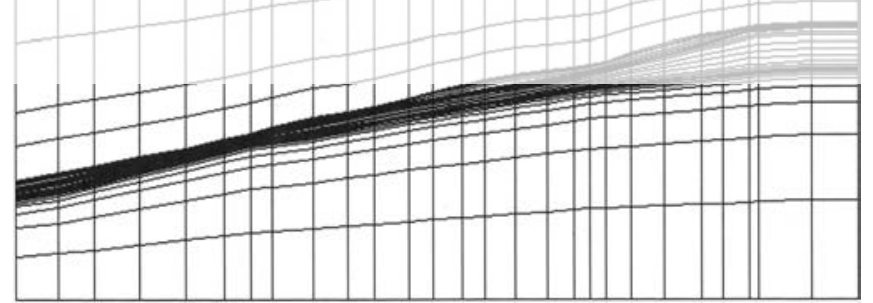

Fig. 14 Mesh for the calculation of initial stress state

lower boundaries define the mechanical boundary conditions.

Initial conditions for this initial phase of calculation are, however, more difficult to establish. There is no information on the in-situ stress state. Oedometer test results, discussed above, indicate that the pre-consolidation stress values of layers $\beta$ and $\gamma$ vary between $2-3$ and 3-4 MPa respectively. Based on this information, an idealised geological sequence - deposition under a N.C. state and erosion of overlying layers - has been simulated. The mesh used in this analysis is shown in Fig. 14. The initial "block" of soil has a vertical dimension which 

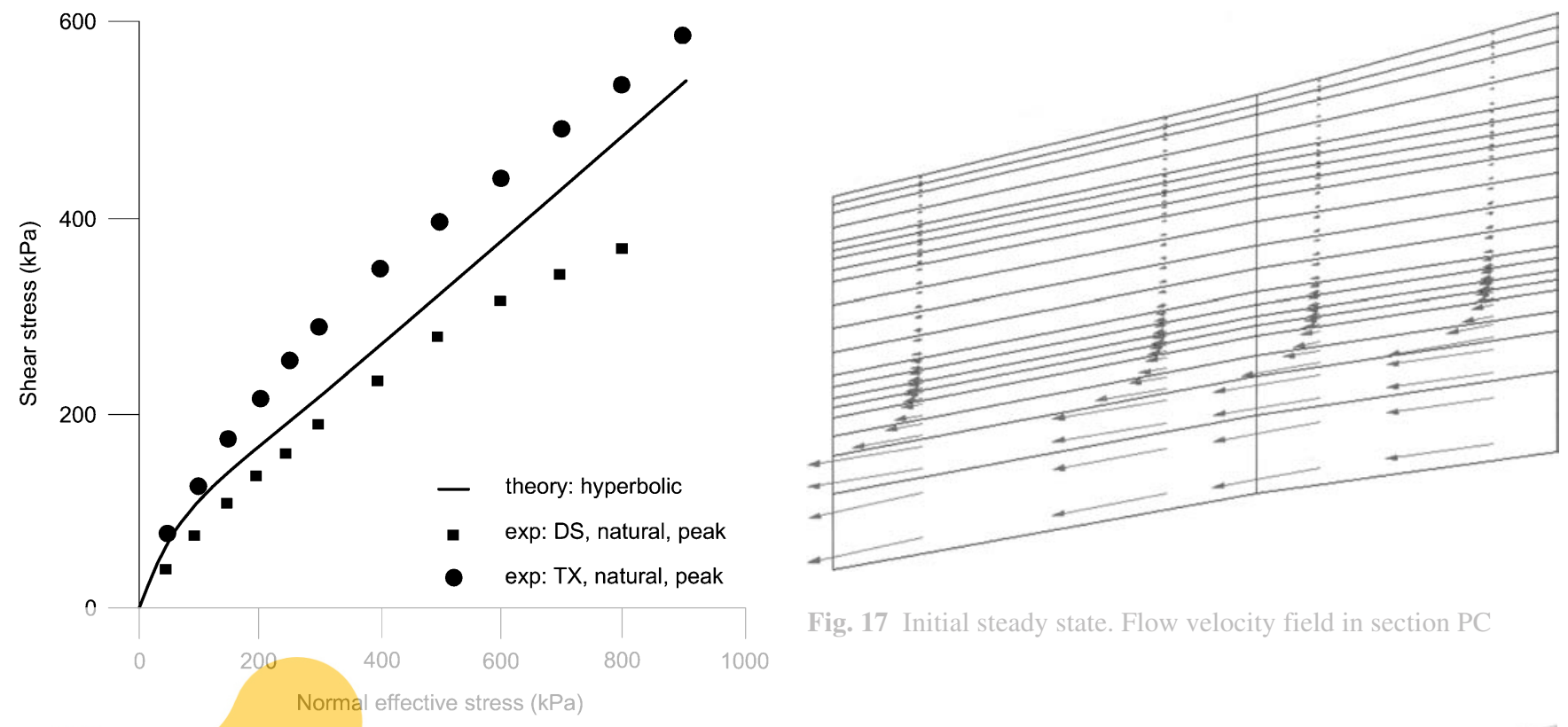

Fig. 17 Initial steady state. Flow velocity field in section PC

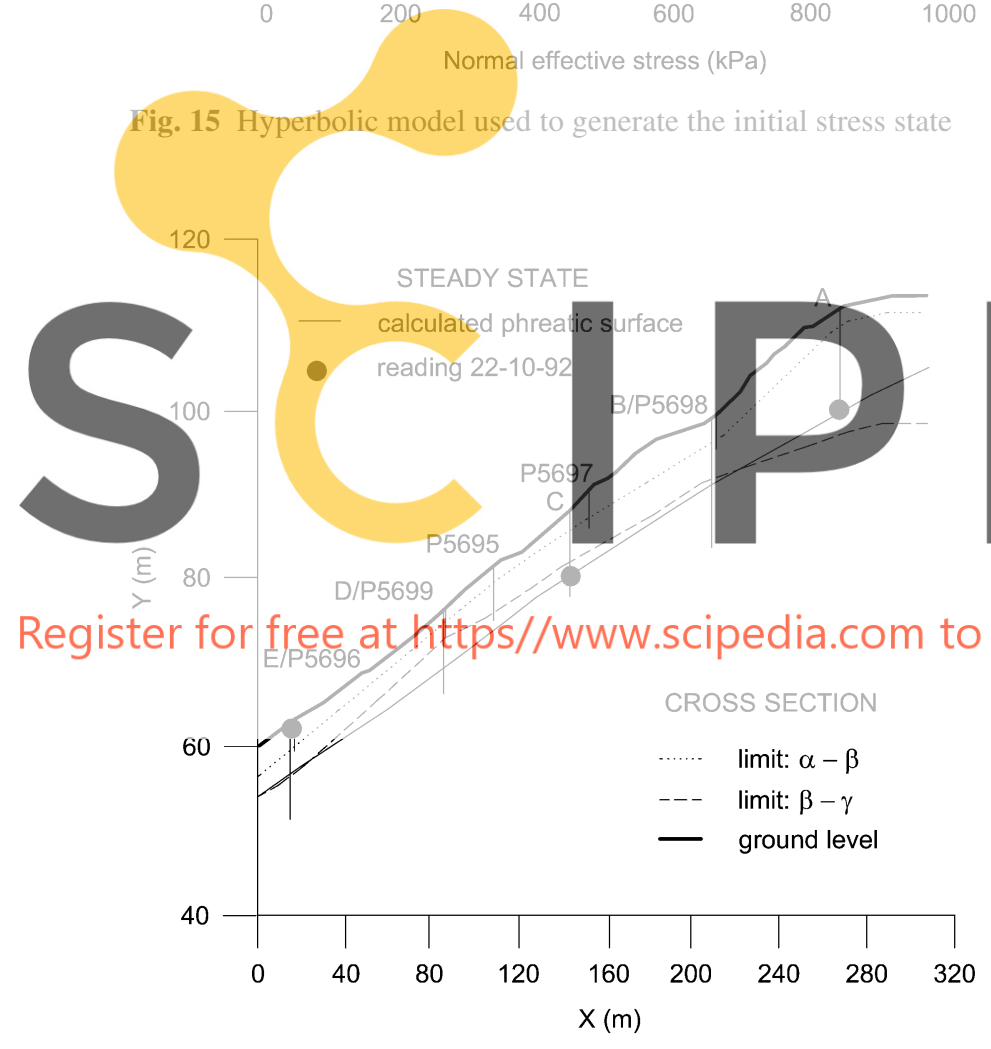

Fig. 16 Calculated phreatic surface

provides a vertical stress $\sigma_{v}=4 \mathrm{MPa}$ at the lower limit of the discretisation. Vertical stresses at the highest and lower levels of the slope are 1.74 and $2.8 \mathrm{MPa}$. All these values are believed to be reasonable in view of oedometer results. The horizontal stresses were derived from the condition $K_{0}=0.52$ obtained in triaxial testing of remoulded samples (Baldelli et al. 1992). For modelling purposes, an elastoplastic hyperbolic model with parameters $c^{\prime}=95 \mathrm{kPa}$ and $\phi^{\prime}=27^{\circ}$ was used. These values correspond to peak strength values measured in triaxial and direct

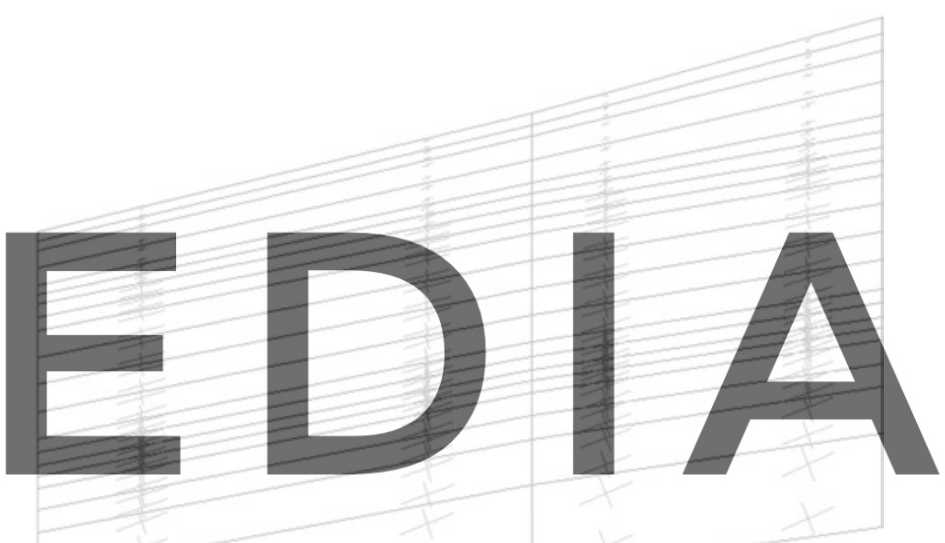

\section{download the version without the watermark}

Fig. 18 Computed initial stresses. Intensity and direction of main stresses are shown

shear experiments, as illustrated in Fig. 15. The initial "block" of soil represented in Fig. 14 was "excavated" until the actual slope geometry was recovered and a set of initial stresses was computed.

Introducing this calculated distribution of initial stresses and the assumed initial values of water (and air) pressures, a calculation was performed using the boundary conditions given in Fig. 13. The computed final phreatic surface (Fig. 16) was very close to actual piezometer readings at the location of boreholes $\mathrm{C}$ and $\mathrm{A}$ (upper and centre parts of the slope). The shallow water table measured at the lower levels (borehole E) in October 1992 could not be reproduced. Some surface recharge at the lower level of the slope would have been required to reproduce the observations at borehole $\mathrm{E}$. However, most of the slope and, in particular, the central sections (B-D) are correctly modelled. The pattern of the 
Table 2 Rainfall infiltration analysis. Cases analysed

\begin{tabular}{lllll}
\hline \multirow{2}{*}{ Case } & \multicolumn{2}{l}{ Saturated water permeability $k_{w s}(\mathrm{~m} / \mathrm{s})$} & & $\begin{array}{l}\text { Number of } \\
\text { different materials }\end{array}$ \\
\cline { 2 - 3 } & Layer $\alpha$ & Layer $\beta$ & Layer $\gamma$ & \\
\hline Steady state (phase A) & $10^{-9}$ & $10^{-9}$ & $10^{-9}$ & 1 \\
a & $10^{-9}$ & $10^{-9}$ & $10^{-9}$ & 1 \\
$\mathrm{~b}$ & $10^{-8}$ & $10^{-9}$ & $10^{-9}$ & 2 \\
$\mathrm{c}$ & $10^{-7}$ & $10^{-9}$ & $10^{-9}$ & 2 \\
$\mathrm{~d}$ & $10^{-6}$ & $10^{-9}$ & $10^{-9}$ & 2 \\
$\mathrm{f}$ & $10^{-8}$ & $10^{-8}$ & $10^{-9}$ & 2 \\
$\mathrm{~g}$ & $10^{-7}$ & $10^{-8}$ & $10^{-9}$ & 3 \\
$\mathrm{~h}$ & $10^{-6}$ & $10^{-8}$ & $10^{-9}$ & 3 \\
$\mathrm{j}$ & $10^{-7}$ & $10^{-7}$ & $10^{-9}$ & 2 \\
$\mathrm{k}$ & $10^{-6}$ & $10^{-7}$ & $10^{-9}$ & 3 \\
\hline
\end{tabular}

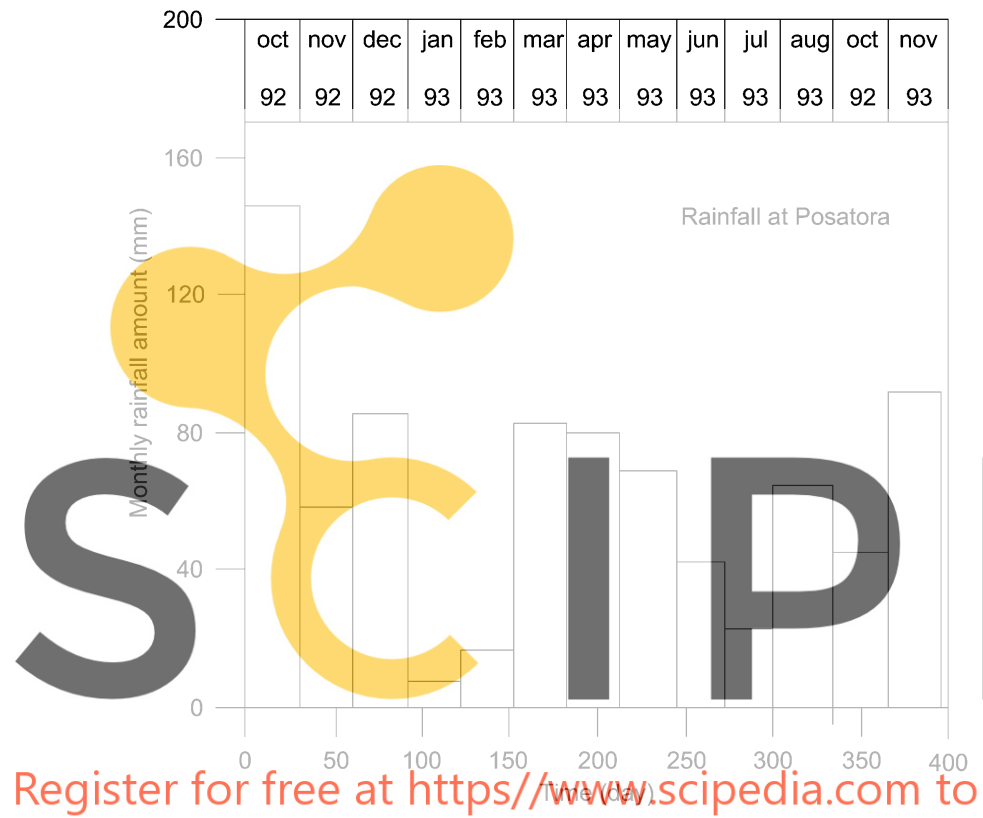

Fig. 19 Rainfall record at Posatora

stationary computed flow is illustrated in Fig. 17 for the central section PC. Downward flow above the water table is restricted due to the reduction of water permeability in the unsaturated soil.

Computed principal stresses for the same central portion of the slope are given in Fig. 18. Large $K_{0}$ values are predicted in upper levels. As expected, $K_{0}$ reduces with depth.

Computed deformations were set to zero at this stage, since it marked the beginning of inclinometer readings.

\section{Rainfall Infiltration}

Probably the greatest uncertainty concerning material properties of the slope lies in the field values of permeability. There were available, however, detailed piezometer records during 13 months - 1 October 1992 to 31 October 1993. These data provided an opportunity to refine

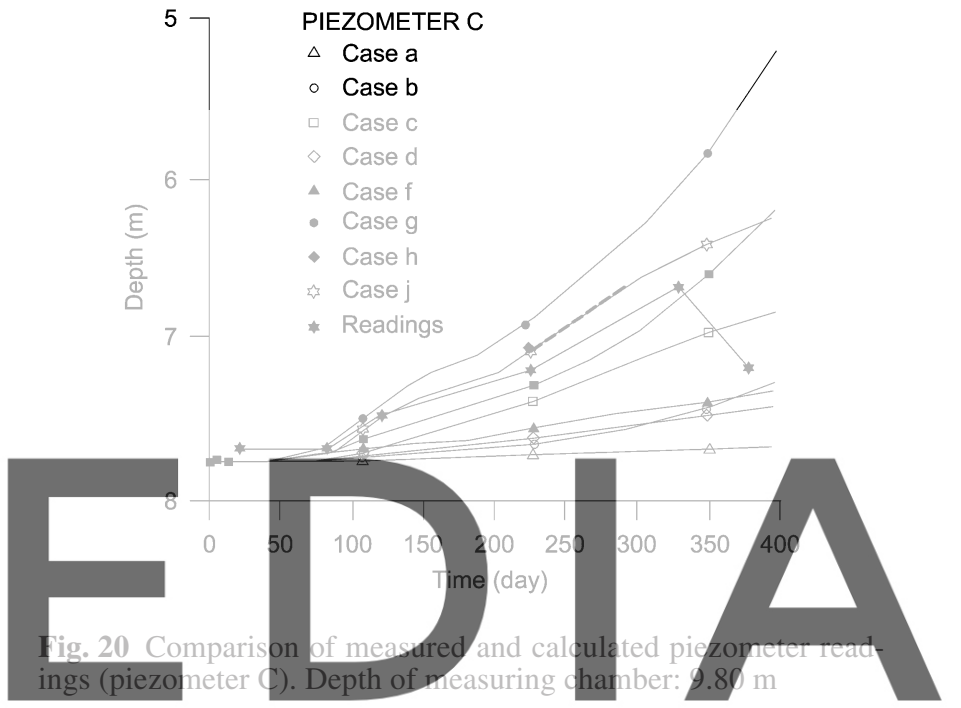

download the version without the watermark the hydraulic model of the slope. To do so, several cases were defined (cases a $-\mathrm{d}, \mathrm{f}-\mathrm{h}, \mathrm{j}$ and $\mathrm{k}$ ) by varying the permeability of layers $\alpha$ and $\beta$. The permeability of the substratum layer $\gamma$ was kept constant. The adopted permeabilities are given in Table 2. Note that case a corresponds to a homogeneous slope.

Permeability to air was changed in similar proportions as permeability to water. However, air flow plays a minor role in this problem.

Computed suction was zero below the phreatic line, and above it the air pressure was essentially zero. Installed piezometers are of two types: open tube (Casagrande), and electrical piezometers. The open tubes were installed in deep borings (A, B, C, D, E) at depths of 10-14 $\mathrm{m}$ and they record fluctuations in the water table. Electrical piezometers were installed at shallower depths (2.80-4 m) within the $\alpha$ layer and were able to record (small) negative water pressures as well as positive values.

The imposed rainfall record, following the criteria discussed above, is shown in Fig. 19. Some comparisons of piezometer readings and calculations are shown in Figs. 20, 21 and 22 for the piezometers C (Casagrande; depth=9.80 m), P5699 (electrical; depth=2.80 m), and 


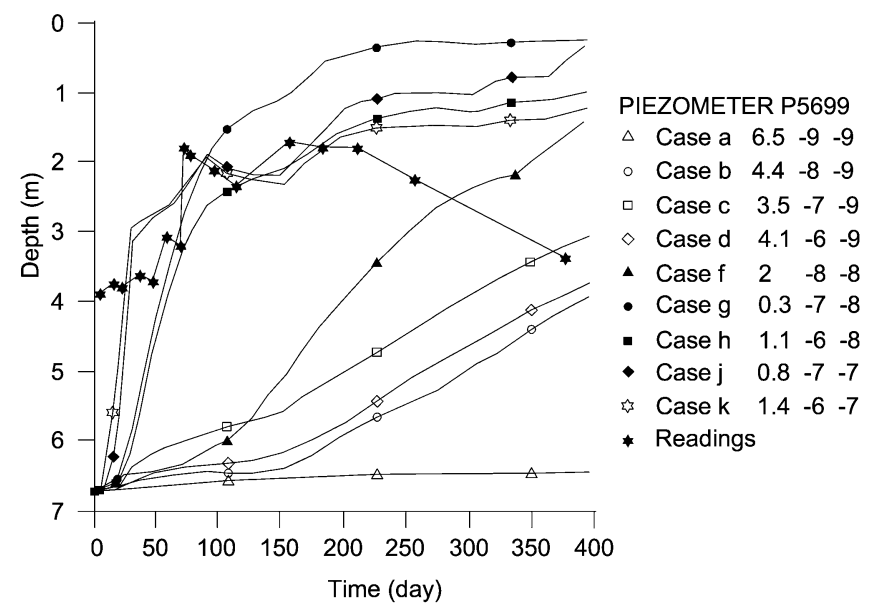

Fig. 21 Comparison of measured and calculated piezometer readings (piezometer P5699). Depth of sensor: $2.80 \mathrm{~m}$

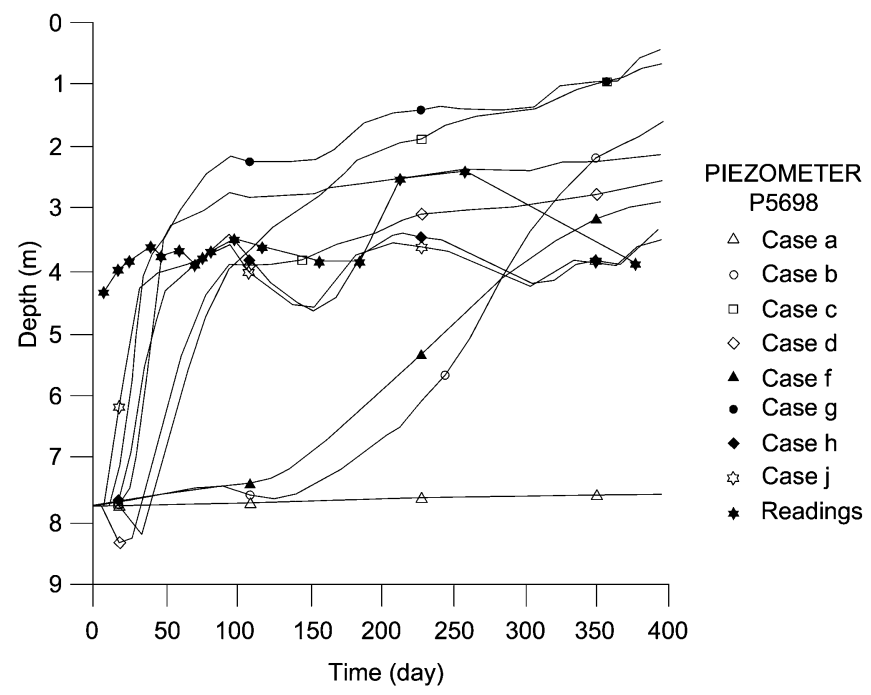

Fig. 22 Comparison of measured and calculated piezometer readings (piezometer P5698). Depth of sensor: $3.15 \mathrm{~m}$

P5698 (electrical; depth=3.15 m). Similar comparisons were made for all the recorded piezometers. In all cases the water pressure is expressed as a depth from the surface. When this depth exceeds the position of the sensor, the pore-water pressure is negative and the corresponding suction may immediately be derived. Note that in the case of shallow piezometers, suctions are often computed for some combinations of layer permeability. Some suction values were also recorded at some particular times.

The general computed trend during the 13-month period was a general elevation of the deep water table (Fig. 20). This trend was essentially followed by calculations except for a drop of water level recorded in the final reading. This is an unexpected fact in view of the rainfall record, which provides a substantial average rain in excess of $80 \mathrm{l} / \mathrm{m}^{2}$ for the 13th month. It is clear that

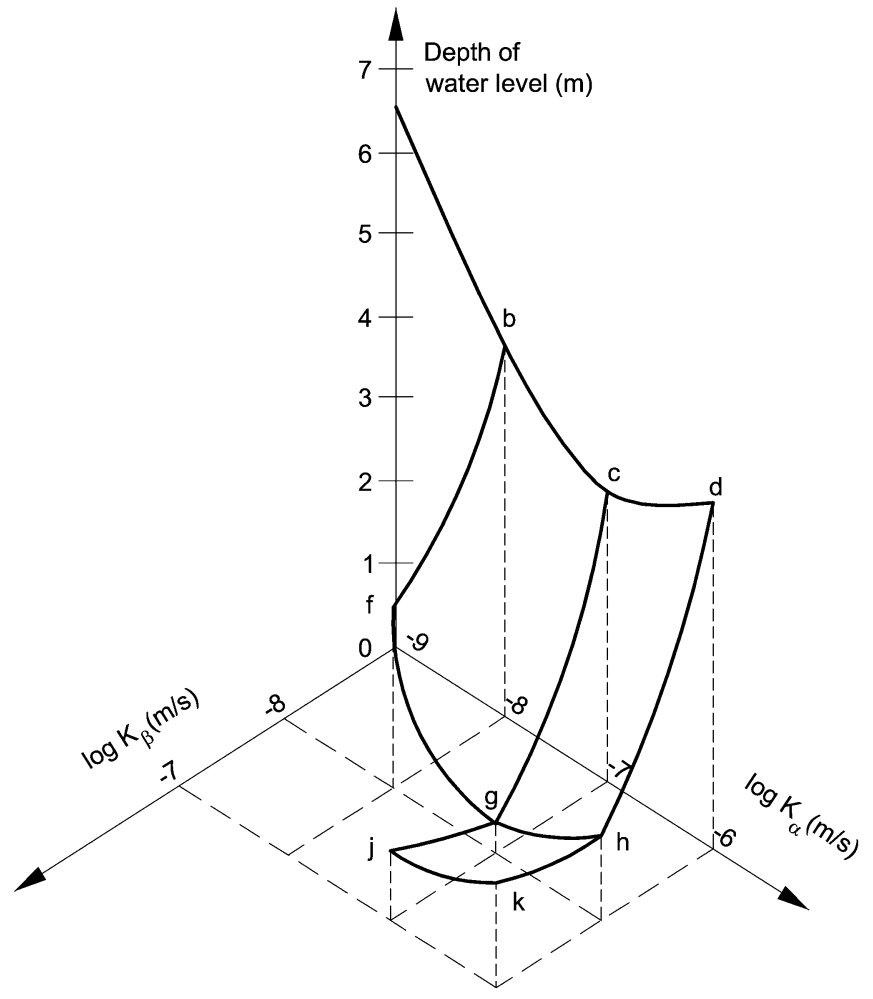

Fig. 23 Computed depth of water level at piezometer P5699 for the time $t=350$ days after the beginning of the prediction exercise (1 October 1992). Depth of sensor: $2.80 \mathrm{~m}$

some combination of layer permeabilities leads to a better reproduction of actual piezometer records. It is also interesting to observe the pattern of computed water pressure predictions as permeability varies among the three layers. There are permeability combinations which lead to the "strongest" response of the slope in terms of the intensity of the generated water pressure at a particular point. This comment is illustrated in Fig. 23, which is a plot of the computed response of piezometer P5699, 350 days after the initial date. The combination $K_{\alpha}=$ $10^{-7} \mathrm{~m} / \mathrm{s}$ and $K_{\beta}=10^{-8} \mathrm{~m} / \mathrm{s}$ leads to the maximum pressure (positive) at the point considered. More or less pervious $\alpha$ and $\beta$ layers result in lower water elevations. It may be concluded that a particular sequence of permeabilities is a critical one for a given rainfall record. There are no easy rules to predict such a critical profile of permeabilities because the computed water pressure is the result of several phenomena: infiltration flow, flow transport parallel to the slope, and (changing) storage capacity of the soil. In fact, the "critical" situation identified for a particular heterogeneity is probably not an absolute concept since it may change with the initial conditions. Nevertheless, this result stresses the relevance of soil permeability and its distribution within the slope to generate critical stability conditions for a given slope geometry, material properties and a given rainfall record.

The nine cases solved were rated from worst to best for each of the piezometer records available, in terms of 


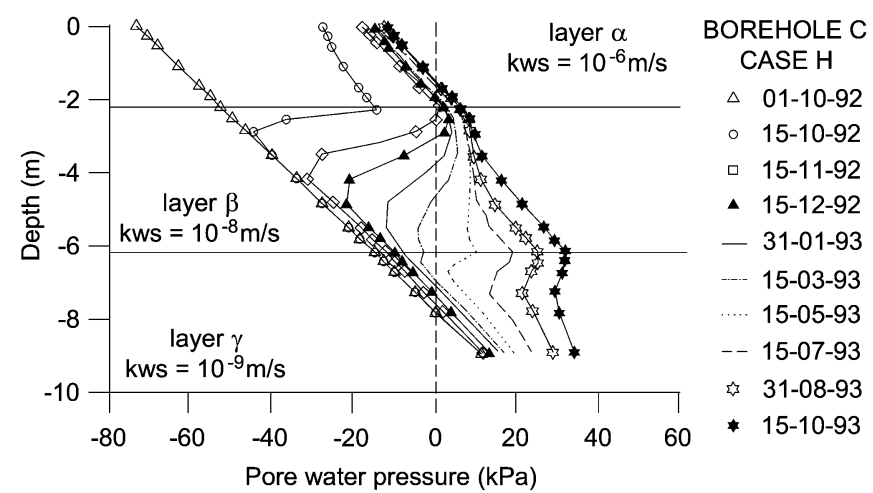

Fig. 24 Computed pore pressures in vertical profile $\mathrm{C}$ (case h: $K_{\alpha}=10^{-6} \mathrm{~m} / \mathrm{s}, K_{\beta}=10^{-8} \mathrm{~m} / \mathrm{s}$, and $K_{\gamma}=10^{-9} \mathrm{~m} / \mathrm{s}$ )

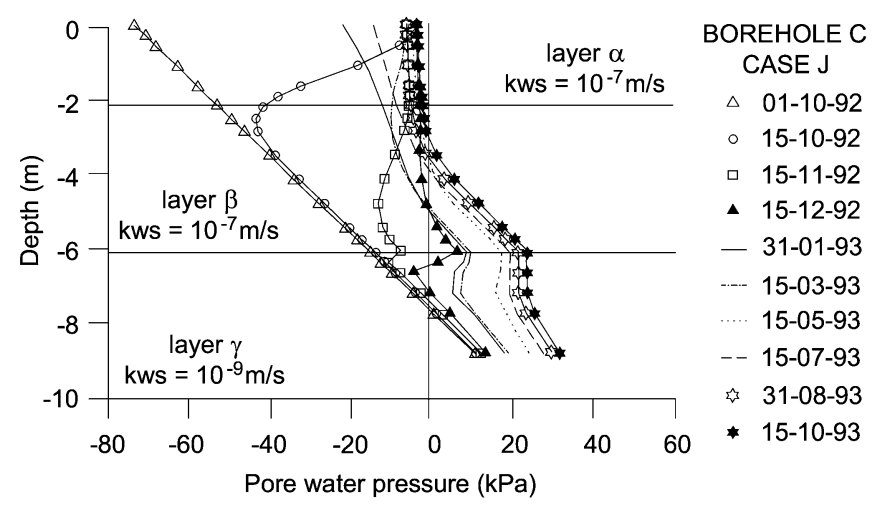

Fig. 25 Computed pore pressures in vertical profile $\mathrm{C}$ (case j: $K_{\alpha}=10^{-7} \mathrm{~m} / \mathrm{s}, K_{\beta}=10^{-7} \mathrm{~m} / \mathrm{s}$, and $K_{\gamma}=10^{-9} \mathrm{~m} / \mathrm{s}$ )

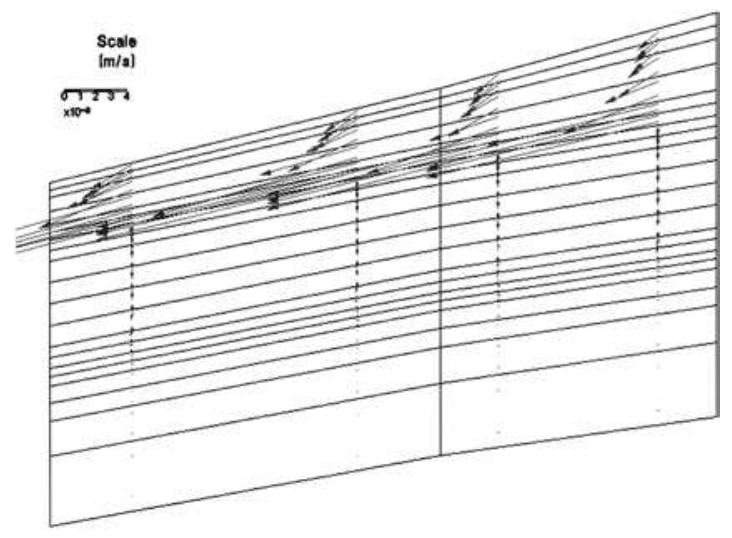

Fig. 26 Computed water velocity field at section PC (case h: $K_{\alpha}=10^{-6} \mathrm{~m} / \mathrm{s}, K_{\beta}=10^{-8} \mathrm{~m} / \mathrm{s}$, and $K_{\gamma}=10^{-9} \mathrm{~m} / \mathrm{s}$ ) at $t=288$ days (15 July 1993)

its proximity to the actual measurements. This procedure of model fitting leads to identifying cases $h, j$ or $k$ as the optimum ones. The worst representation was given by model a, the uniform slope. Figures 24 and 25 show the computed evolution of pore-water pressures in the soil profile at borehole $\mathrm{C}$ for the cases $\mathrm{h}\left(K_{\alpha}=10^{-6} \mathrm{~m} / \mathrm{s}\right.$;

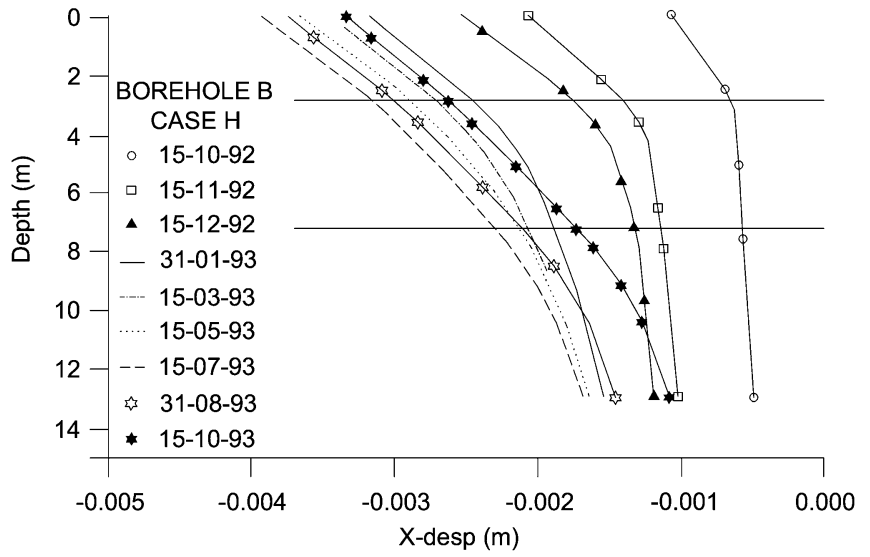

Fig. 27 Computed vertical profile of slope displacements at borehole B (case h)

$K_{\beta}=10^{-8} \mathrm{~m} / \mathrm{s}$, and $\left.K_{\alpha}=10^{-9} \mathrm{~m} / \mathrm{s}\right)$ and $\mathrm{j}\left(K_{\alpha}=10^{-7} \mathrm{~m} / \mathrm{s}\right.$; $K_{\beta}=10^{-7} \mathrm{~m} / \mathrm{s}$, and $K_{\alpha}=10^{-7} \mathrm{~m} / \mathrm{s}$ ).

In case $\mathrm{h}$, the strong transition of permeabilities between the upper layers $\alpha$ and $\beta$ leads to an accumulation of water at their interface. Positive pore-water pressures at this interface are computed some time after the action of rainfall. In case $j$, layers $\alpha$ and $\beta$ have the same permeability $\left(10^{-7} \mathrm{~m} / \mathrm{s}\right)$, and a suction is maintained at this interface throughout the modelled time period. This case leads to a smoother variation of pore pressures at depth. The rain infiltration modifies substantially the downward flow of water (Fig. 26), if compared with the initial state. The upper soil levels, which have approached saturation, carry increased flows toward the slope toe.

Given these results, the mechanical analysis was limited to cases $h, j$ and $k$, since it became clear that a transition of permeabilities from higher values at the surface and lower values at depth was required to match piezometer readings.

\section{Deformation Analysis and Evaluation of Safety Factors}

Calculated deformations will now be compared with slope displacements measured in inclinometer B (upper part of the slope: section IB in Fig. 9). The reference zero reading for the inclinometer was taken on 22 September 1992, a few days before the initial time for calculations (1 October 1992). Computed displacements for one of the reference cases selected (case h) are shown in Fig. 27. Maximum surface displacements are small, in the order of a few millimetres. A comparison of the measured evolution of horizontal displacements and calculated ones at a point near the surface (depth $=0.30 \mathrm{~m}$ ) at borehole B is shown in Fig. 28. The three reference cases ( $h, j, k)$ provide similar results (Fig. 27). The agreement is acceptable during the first 7 months. Sometime later, the upper part of the slope experiences a sudden motion which is not captured by the deformation model. The 


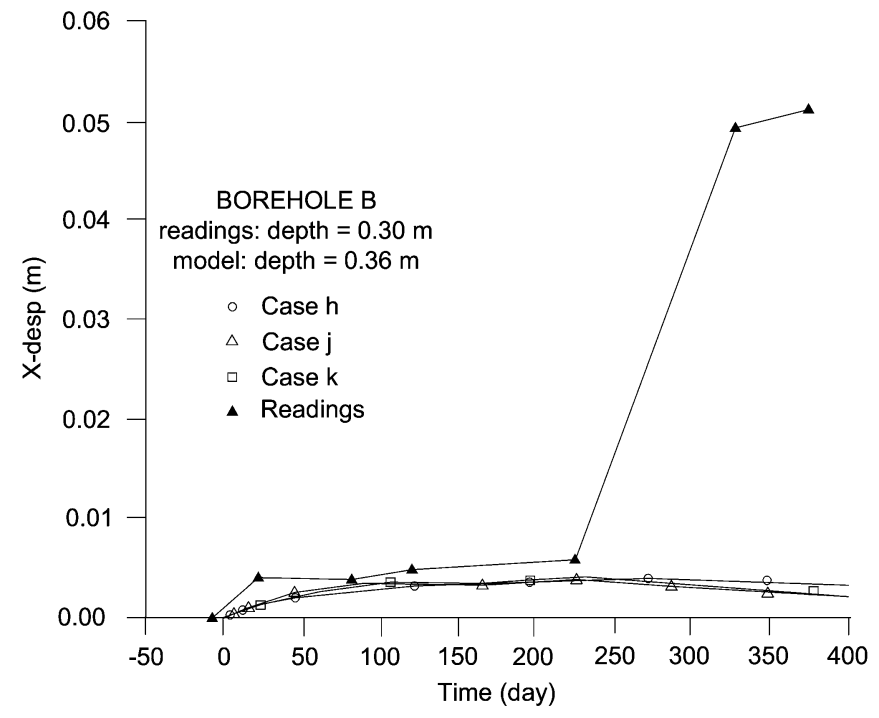

Fig. 28 Computed and measured horizontal displacements of the slope at a point located $0.30 \mathrm{~m}(0.36 \mathrm{~m})$ below the surface at borehole B

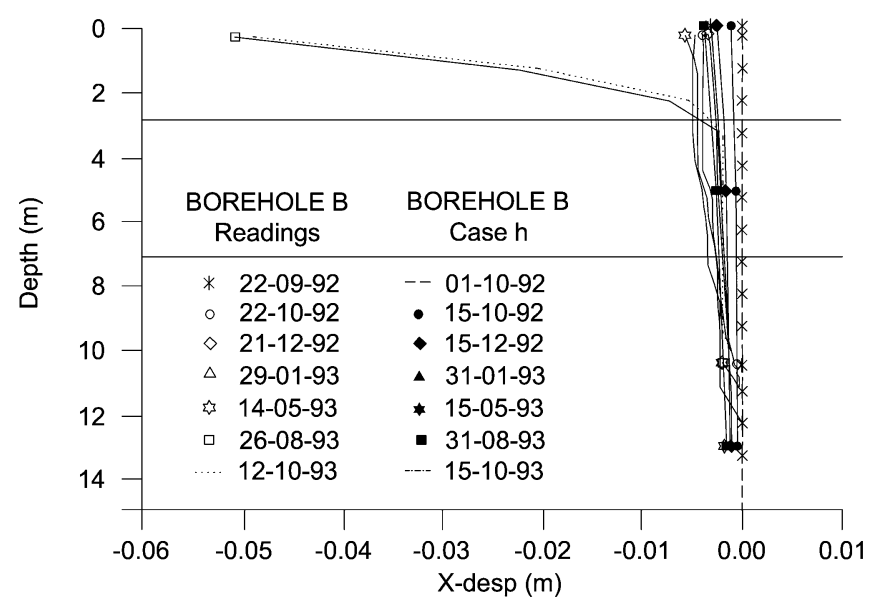

Fig. 29 Computed and measured profiles of horizontal displacements at borehole B

displacement profile along depth (Fig. 29) shows that this sudden motion essentially displaces the upper "reworked" layer $\alpha$. It seems that, at the interphase between the $\alpha$ and $\beta$ layers, a distinct shear surface has developed (or it was already formed). The non-linear elastic model is obviously not able to reproduce this behaviour. Instead, it provides the pattern of deformation associated with the soil volume change as suction changes as a result of rainfall. Figure 30 is, in this regard, a deformed mesh of the slope for case $\mathrm{h}$ (the other reference cases provide very similar results). The clay expansion, which results in increasing displacements as the slope surface is approached, also induces downward components of movement. These downward displacements are small (a few millimetres) but they have consistently been measured. No information on vertical displacements was, however, available.

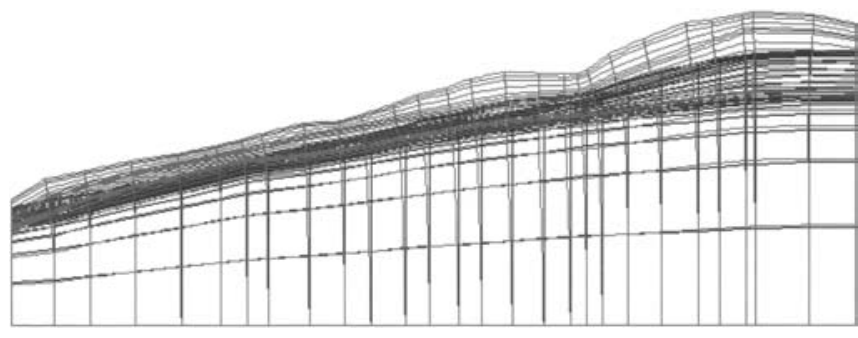

Fig. 30 Computed deformation of the slope 335 days after the initial state (case h)

An additional insight into the problem is gained from another perspective. Local safety factors have been computed as a ratio of shear strength and existing shear stress. For an infinite slope the classical expression for a planar failure is:

$F_{(i s)}=\frac{c^{\prime}+\left(\gamma d \cos ^{2} \alpha-p_{w}\right) \tan \varphi^{\prime}}{\gamma d \sin \alpha \cos \alpha}$

where $d$ is the depth below surface, $\gamma$ the total specific weight, and $\alpha$ the slope angle $\left(\alpha \cong 11^{\circ}\right)$. The analysis performed provides $p_{w}$ as a function of time for every point within the slope, and therefore Eq. (1) may be computed.

Since stresses $\left(\sigma_{x}, \sigma_{y}, \tau_{x v}\right)$ are also known from the F.E. analysis, an alternative to Eq. (1) may be computed as follows:

$$
\begin{aligned}
& F_{(F E M)}= \\
& \frac{c^{\prime}+\left[\frac{\left(\sigma_{x}+\sigma_{y}\right)}{2}-\frac{\left(\sigma_{x}-\sigma_{y}\right)}{2} \cos 2 \alpha-\tau_{x y} \sin 2 \alpha-p_{w}\right] \tan \varphi^{\prime}}{\frac{\left(\sigma_{x}-\sigma_{y}\right)}{2} \sin 2 \alpha-\tau_{x y} \cos 2 \alpha}
\end{aligned}
$$

The evolution of vertical profiles of local safety factors has been represented in Figs. 31 and 32 for a homogeneous slope at borehole $\mathrm{C}$ (centre of the slope). In this case a common failure envelope adopted for layer $\beta$ (see Figs. 4 and 12) is assumed for the whole slope. The permeability profile corresponds to case $\mathrm{h}$. The FEM-based safety factor is smaller, within the upper $\alpha$ layer (and, specifically, at the critical interphase with layer $\beta$ ), than the infinite slope-based value. A minimum safety factor is computed at the $\alpha-\beta$ interface. However, absolute values are high, far from explaining failure. Consider, however, the heterogeneous case in which soil strength of layer $\alpha$ is approximated by the remoulded strength values, given also in Figs. 4 and 12. The profiles of local safety factors (FE-based calculations) are given in Fig. 33 for case h, and in Fig. 34 for case j. Safety factors in the upper reworked layer reach low values at some particular times. The interphase between $\alpha$ and $\beta$ layers is a critical surface, since it marks the change in permeability and shear strength. Minimum safety factors are computed at this interphase.

The choice of a remoulded strength for the $\alpha$ layer and, in particular, for the $\alpha-\beta$ interphase may be justified 


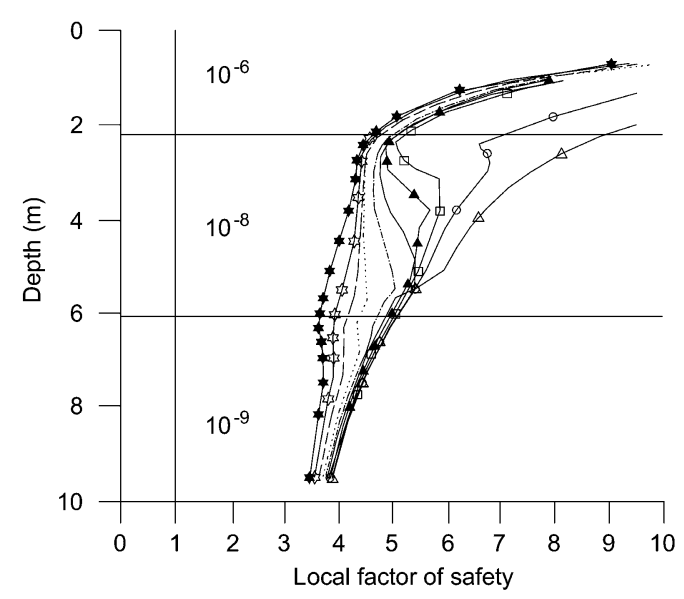

Fig. 31 Profiles of local safety factor (based on an infinite slope analysis) at borehole C (case h, homogeneous strength)
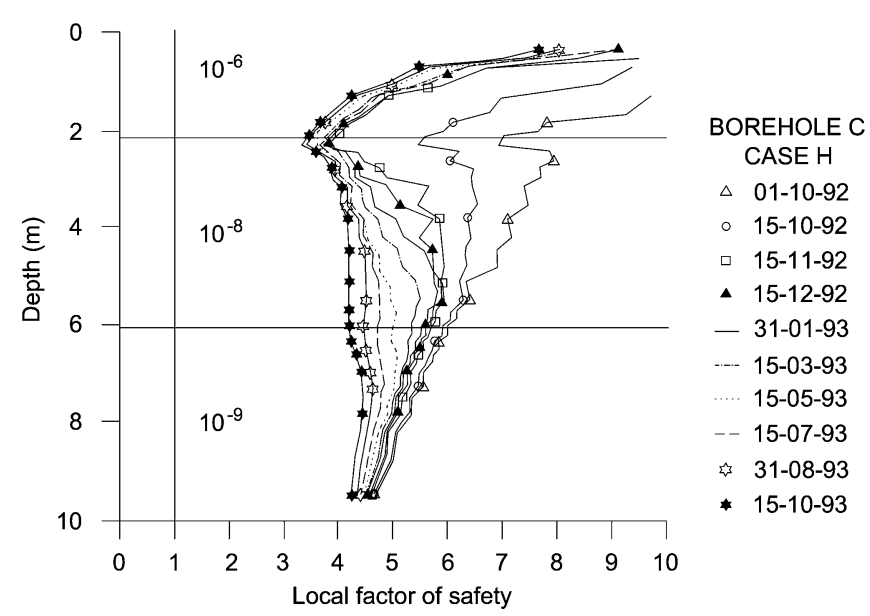

Fig. 32 Profiles of local safety factors (based on FE computations) at borehole $\mathrm{C}$ (case h, homogeneous strength)

on the basis of the physical processes taking place at the upper weathered layer. Inclinometer readings (Fig. 29) show that displacements are concentrated in the $\alpha$ layer and therefore, the $\alpha-\beta$ interphase will undergo large shear strains or even a distinct shear surface, as mentioned above. This natural remoulding effect reduces the soil strength. As a result, strength parameters determined in remoulded specimens may be appropriate for stability evaluation (as the computed safety factors tend to suggest). The presence of sand lenses in $\alpha$ and $\beta$ layers may also have some effect. When sand lenses are continuous, they tend to channel the internal flow within the slope and they may reach transient high pressures as a result of external recharge (heavy rainfall in the area). Then, effective stresses and available strength will drop to critical values. However, measured pore-water pressures in piezometers, recorded over a significant time period, do not show abnormally high values. Nevertheless, the de-

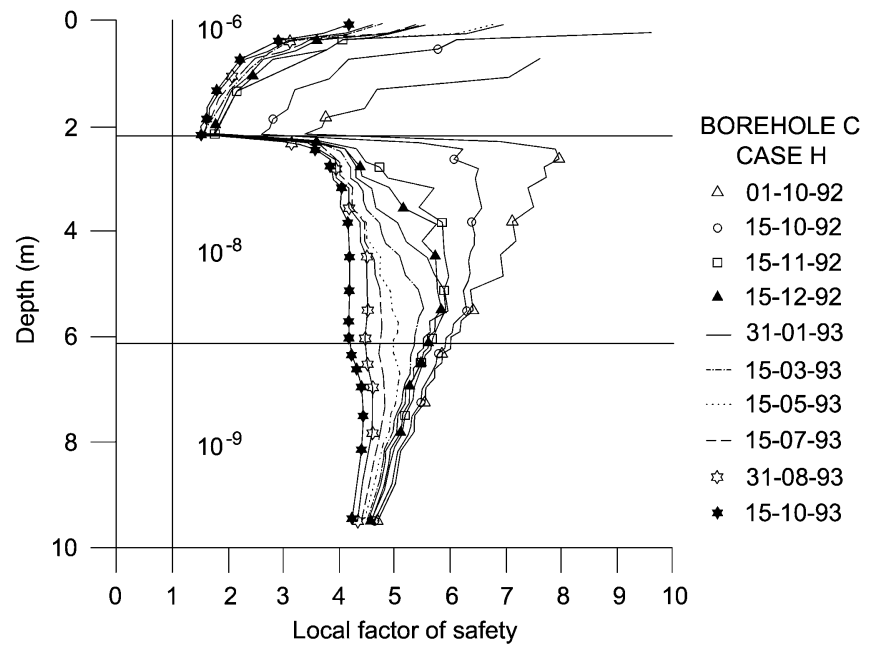

Fig. 33 Profiles of FE-based local safety factors at borehole $\mathrm{C}$ (case h, heterogeneous strength)

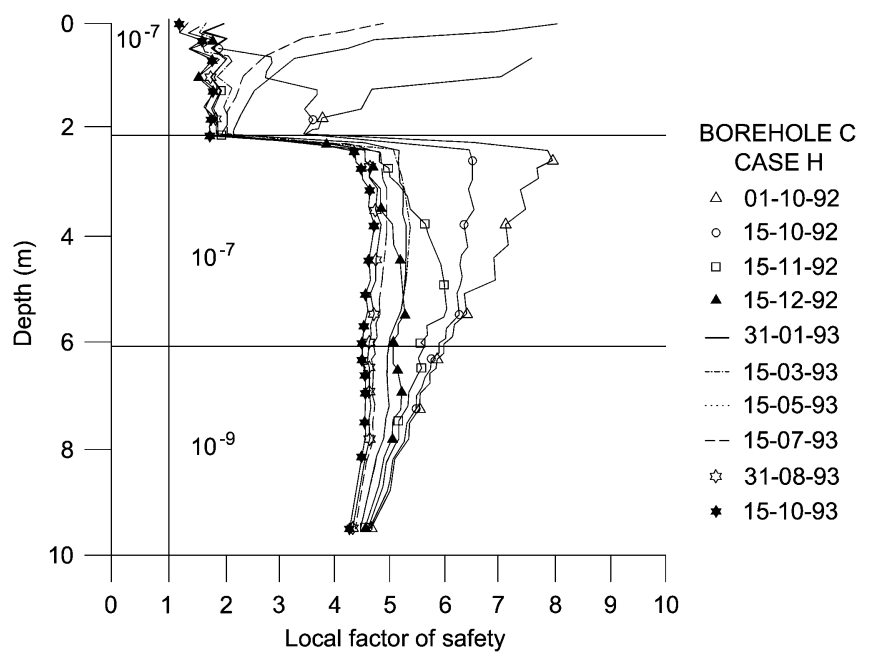

Fig. 34 Profiles of FE-based local safety factors at borehole C (case $\mathrm{j}$, heterogeneous strength)

tailed characterization of the hydrological regime of a heterogeneous slope, such as the Villa Blasi slope, cannot be performed on the basis of available data and it is probably an unrealistic proposition in most situations.

If a point within the upper $\alpha$ layer is selected, the influence of climate (rainfall) is better appreciated when the computed local safety factor is plotted with time. This is shown in Fig. 35 for a point at a depth $=2.15 \mathrm{~m}$ at the position of borehole $\mathrm{C}$ (central zone of the slope). Equations (1) and (2) are represented for the base "hydraulic" cases (h, j, k). FE-based safety factors are consistently lower than their infinite slope-based counterparts. This is explained by the significant influence of the method followed to find initial stresses, hopefully closer to real conditions. The fluctuating rainfall record may be followed in Fig. 35. The safety factor decreases in correspondence with the wet season, and it increases when the rainfall inflow decreases. This is the reason for 


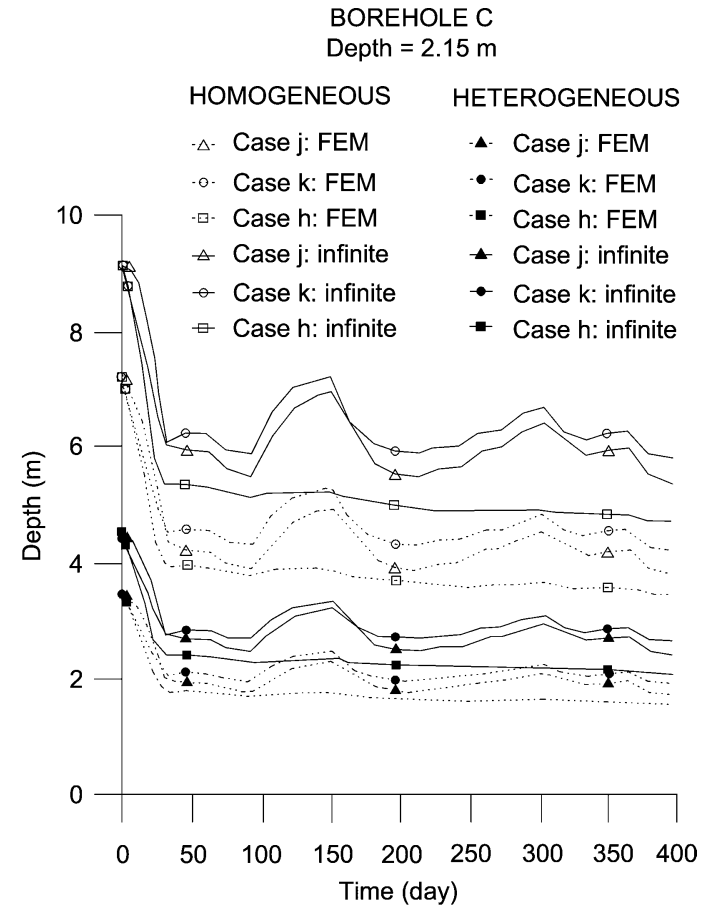

Fig. 35 Evolution of local safety factors at a depth of $2.15 \mathrm{~m}$, borehole C. Infinite slope and FE-based cases homogeneous and heterogeneous strength and three hydraulic base cases are represented

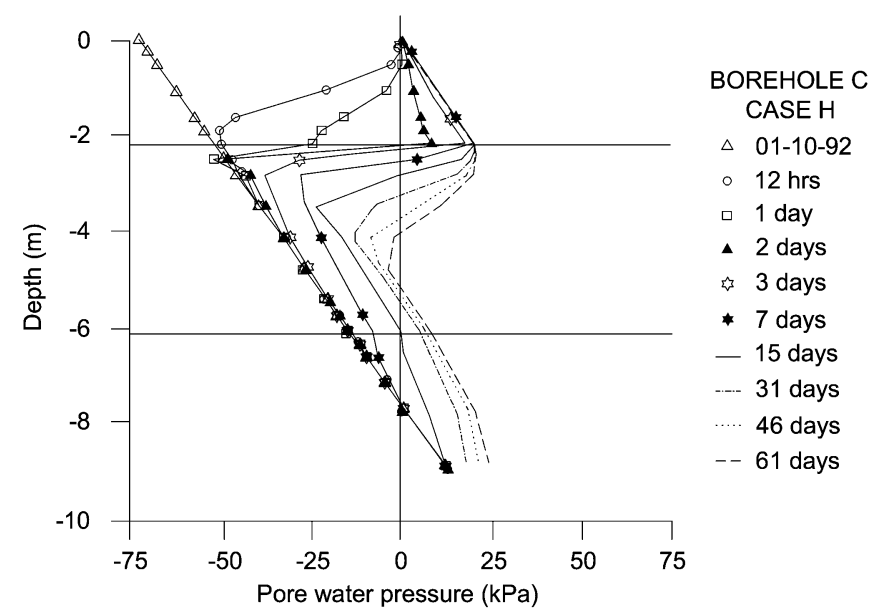

Fig. 36 Profiles of water pressure for a permanent slope flooding. Case $\mathrm{h}$

the increase in safety factor observed after a dry season in January 1993. The maximum computed fluctuation in safety factor (FE-based, heterogeneous strength distribution), once the initial transient period is discarded, is around $\Delta F=0.6$ at a depth of $2.15 \mathrm{~m}$. Larger fluctuations (shown in Fig. 35) are computed for other circumstances. Presumably extreme rainfall events may take the slope to a limiting failure condition $(F=1)$ in the case plotted in Fig. 35. The steady but slow decrease in safety factor observed in the figure follows the reduction in suction in the upper layer.

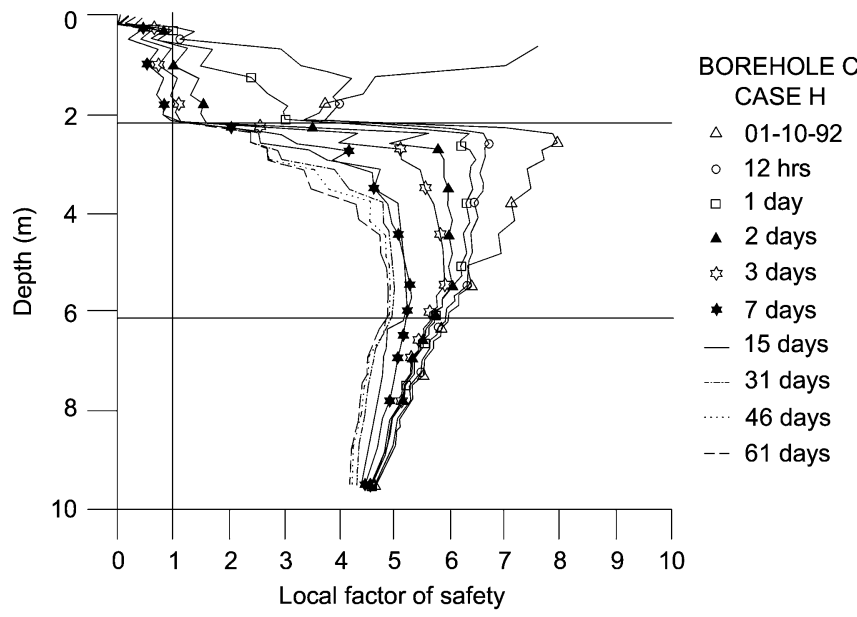

Fig. 37 Profiles of FE-based local safety factor. Heterogeneous strength distribution. Case $h$

The effect of an extreme rainfall event was finally investigated. The hypothesis is now that the intensity of rain is, at all times, larger than the infiltration capacity. This condition is simulated by flooding the slope. A zero water pressure is then applied as a boundary condition in the upper slope boundary. This condition was maintained for 61 days.

The evolution of water pressures in the slope at section $\mathrm{C}$ is shown in Fig. 36 for the reference case $\mathrm{h}$. Shortly after $24 \mathrm{~h}$ of continuous rain, a perched water table develops over the interphase between layers $\alpha$ and $\beta$. A hydrostatic positive pore-water pressure develops in layer $\alpha$ after a week of rain. Suction in the $\beta$ layer progressively decreases and extensive zones develop positive pore-water pressures with time. The elevation of the deep water table also increases beyond the first week. This evolution of water pressures is matched by parallel changes in safety factor (FE-based, heterogeneous strength distribution) (Fig. 37). Safety factors lower than 1 are computed at the $\alpha-\beta$ interface for times beyond the first seven days of flooding. Lower values are computed at higher levels. However, the layer $\beta$ of undisturbed brown clay remains stable even after 2 months of surface flooding.

\section{Discussion and Conclusions}

Two deformation mechanisms may be identified in the slope analysed: a creep-type displacement which was detected along the full depth of the soil investigated (around $12 \mathrm{~m}$ ), and a surface planar slide. The first mechanism is interpreted as a deformation associated with volume changes of the overconsolidated clays as the water pressures change in time as a reaction to rainfall events. Porewater pressures in the slope do not follow a simple model. A rather deep but fluctuating water table affects the clay substratum. However, water pressures at the upper two weathered layers are controlled by the atmospheric weather. Positive or negative water pressures are recorded at different positions or times during the year. A fairly 
good agreement between computed and measured water pressures is achieved when the three identified layers are characterised by three different permeabilities.

An interesting conclusion of the sensitivity analysis performed regarding the influence of heterogeneous distribution of permeability is that the critical situation of a given slope (in the sense of reacting with the maximum development of water pressures) for a given climatic record is obtained for a given combination of layer permeabilities. From another perspective, this result also indicates that, given a soil profile and geometry and its associated permeabilities and additional water flow parameters, there exist rainfall records which lead to a maximum "reaction" of the slope in terms of pore-water pressure development. Permeability and water retention are therefore fundamental properties in slope stability analysis, a fact often overlooked in engineering analyses.

The analysis performed indicated that downward as well as heave displacements are to be expected in the slope. Only lateral displacements, as recorded in inclinometers, were, however, available. Slopes in expansive natural clays are often known to present stability problems. A primary cause for this situation is probably associated with downward displacements which result from the cyclic expansion/shrinkage induced by suction changes as a consequence of weather changes. The upper layers undergo the maximum suction and volumetric deformation changes, and they are prone to develop the upper sliding mechanism identified also in the slope analysed. Probably, as deformation accumulates, peak strengths are attained and, eventually, remoulded and even residual strength conditions develop. Weathering mechanisms result also in a change in permeability, which is stronger the closer to the surface. In fact, the water pressures recorded are consistent with a decrease of permeability with depth. One of the acceptable soil permeability profiles is the sequence $\left(10^{-6}, 10^{-8}\right.$, $10^{-9} \mathrm{~m} / \mathrm{s}$ ) for the three clay layers identified from top to bottom. It has been shown that permeability transitions lead to peak pressures computed at the interphases (see, for instance, Fig. 24). Both effects - strength degradation due to accumulated straining, and peak water pressures (positive or negative) - may well result in the development of a sliding surface at an interface. This seems to be the case for the Villa Blasi slope, where the upper $\alpha$ horizon of remoulded weathered clay is apparently sliding on its contact with the underlying, weathered, brown Ancona clay.

The coupled hydromechanical model used to analyse the slope is unable to reproduce the sliding mechanism but it has been used to compute local sliding safety factors. This type of analysis also provides interesting information, which is always useful in slope stability analysis. Two procedures have been used to derive local safety factors. Both share the hypothesis of infinite slope, which is considered acceptable in this case. In the first procedure, local safety factors are computed following the classical expression for infinite slope as a ratio of available shear strength and shear stress in equilibrium with the overburden weight. Water pressures (positive and negative), required for strength calculations, are given by the FE analysis. In the second approach, both stresses and pore pressures, derived from the hydromechanical analysis, are the input for the safety factor. Relevant differences were found for the two types of analyses, a result which highlights the importance of an adequate estimation of initial stresses in slope stability calculations.

The computed distributions and evaluations of local safety factor illustrate also the singularity of the interphase between the upper reworked $\alpha$ layer and the underlying brown clay layer $\beta$. Minimum safety factors are consistently found at this position. However, under the imposed rainfall history measured in one year, failure conditions are not found at this interphase if the strength parameters of the weathered $\beta$ layer (lower envelope of peak resistances) are adopted for the whole profile.

If the strength of the upper layer is reduced to values measured for reconstituted samples $\left(c^{\prime}=0 ; \phi^{\prime}=24.5^{\circ}\right)$, safety factors at the $\alpha-\beta$ interphase drop to values close to 1.5 at the end of the rainfall period analysed. Additional analyses, which attempt to simulate extreme weather conditions (heavy and prolonged rainfall), indicate that a failure along the interphase is possible even if the strength parameters are maintained at the measured remoulded values. Probably, this was the case for a first sliding in the past history of the slope. Then, strength values would be even reduced and would be closer to residual conditions. Under these circumstances, "normal" rainfall records could trigger additional sliding, as shown by the inclinometer readings during the period October 1992 to October 1993.

Once a planar sliding surface has developed, the conceptual model of slope motion is simple in principle: the upper reworked layer slides on top of a critical surface at residual or near-residual conditions. Even in this case, however, the periods of activity are dictated by the suction changes in the upper few metres which depend critically on the slope geometry, flow boundary conditions, rainfall record, flow parameters (permeability, water retention properties) and its spatial variation. The problem maintains its complexity and shows the dependence of slope safety on climate, geometry and a number of constitutive parameters.

The case record analysed illustrates the relationships among the various factors controlling slope stability along a heterogeneous clay profile. It also points to the difficulties encountered in practice and the need for accurate, comprehensive and long records of behaviour in situ. Modern computational methods, which couple mechanical and hydraulic conditions under saturated or unsaturated conditions, are powerful tools to interpret field performance.

Acknowledgements The authors are thankful to the support provided by the EU through the EPOCH Project EPOC-CT90-0033, Physical Processes in the Mediterranean Climates and Related Slope Instabilities in Overconsolidated Clayey Soils, coordinated by Professor Scarpelli. 


\section{Appendix}

\section{Mathematical Formulation of the Flow-deformation Model}

Continuity and equilibrium equations

- Continuity of the air mass filling the soil voids

$$
\frac{\partial}{\partial \mathrm{t}}\left[\rho_{a} n\left(1-S_{r}+H S_{r}\right)\right]+\operatorname{div}\left[\rho_{\mathrm{a}}\left(\mathbf{v}_{a}+H \mathbf{v}_{w}\right)\right]=0
$$

- Continuity of the water mass filling the soil voids

$$
\frac{\partial\left(\rho_{w} n S_{r}\right)}{\partial t}+\operatorname{div}\left(\rho_{w} \mathbf{v}_{w}\right)=0
$$

- Mechanical equilibrium

$$
\frac{\partial\left(\sigma_{i j}-\delta_{i j} p_{a}\right)}{\partial x_{j}}+\frac{\partial p_{a}}{\partial x_{i}}+b_{i}=0(i=1.3)
$$

where $\rho_{a}, \rho_{w}$ are air and water mass densities, $n$ the soil porosity, $S_{r}$ the degree of saturation, and $H$ Henry's constant. Vectors $\mathbf{v}_{\mathrm{a}}$ and $\mathbf{v}_{\mathrm{w}}$ refer to air and water velocities (in the Darcy sense). $p_{a}$ is the air pressure, $p_{w}$ the water pressure, $\sigma_{i j}$ the total stress, $b_{i}$ the body forces, $x_{i}$ the system coordinates, and $\delta_{i j}$ the Kronecker's symbol. Note that the equilibrium is formulated in terms of net stresses (excess of total stresses over air pressure). When the soil becomes saturated, $p_{a}=p_{w}$, suction $s=p_{a}-p_{w}$ becomes zero and the classical formulation in effective stresses is recovered.

The displacement vector $(\mathbf{u})$, and the air and water pressures $\left(p_{a}\right.$ and $\left.p_{w}\right)$ are chosen as basic variables of the problem. To solve the basic equations (3), (4) and (5) in terms of these basic variables, a set of constitutive and motion equations are necessary.

\section{Constitutive and motion equations}

Air. It is assumed that the air behaves as an ideal gas. Density and pressure are related as follows:

$\rho_{a}=\frac{M}{R T} p_{a}=\beta p_{a}$

where $T\left({ }^{\circ} \mathrm{K}\right)$ is the absolute temperature, $R$ the gas constant, $M$ the molecular weight of air, and $\beta$ is the compressibility of air.

Motion of air can be described by a generalization of Darcy's law:

$\mathbf{v}_{a}=-K_{a}\left(1 / \gamma_{a} \nabla p_{a}+\nabla z\right)$

where $K_{a}$ is the coefficient of permeabilitiy and $\gamma_{a}$ the specific weight of air.

The coefficient of permeability varies strongly with $S_{r}$ and, to a lesser extent, with the void ratio (e). Typical specific expressions proposed by Yoshimi and Osterberg (1964) for $K_{a}$ versus $e$ and $S_{r}$, and by Brun (1989) for $K_{a}$ versus $\left(p_{a}-p_{w}\right)$ are:

$$
\begin{aligned}
& K_{a}\left(e, S_{r}\right)=A_{g} \frac{\gamma_{a}}{\mu_{a}}\left[e\left(1-S_{r}\right)\right]^{\beta_{a}} \\
& K_{a}\left(p_{a}-p_{w}\right)=\frac{A_{a} K_{a s}}{A_{a}+\left(C_{a}\left(p_{a}-p_{w}\right)\right)^{-B_{a}}}
\end{aligned}
$$

where $K_{a s}, A_{g}, \beta_{a}, A_{a}, B_{a}$ and $C_{a}$ are constants, and $\mu_{a}$ is the viscosity of the air.

Water. Water flow is described by a generalization of Darcy's law:

$\mathbf{v}_{w}=-K_{w} \nabla\left(p_{w} / \gamma_{w}+z\right)$

where $K_{w}$ is the coefficient of permeability and $\gamma_{w}$ the specific weight of water (assumed constant).

Several empirical expressions have been given for the $K_{w}-\left(p_{a}-p_{w}\right)$ or $K_{w}-\left(S_{r}, e\right)$ relationship. Jacquard (1988) proposed:

$K_{w}\left(p_{a}-p_{w}\right)=\frac{A_{w} K_{w s}}{A_{w}+\left(C_{w}\left(p_{a}-p_{w}\right)\right)^{B_{w}}}$

To combine the effects of void ratio and saturation, Lloret and Alonso (1980) proposed to use a product of the variation of permeability with void ratio proposed by Lambe and Whitman (1968), and the variation with degree of saturation proposed by Irmay (1954):

$K_{w}\left(e, S_{r}\right)=A_{l}\left(\frac{S_{r}-S_{r u}}{1-S_{r u}}\right)^{3} 10^{\vartheta e}=K_{w}^{o}\left(\frac{S_{r}-S_{r u}}{1-S_{r u}}\right)^{3}$

In Eqs. (11) and (12), $K_{w s}, A_{w}, B_{w}, A_{l}, S_{r u}, K_{w}^{\mathrm{o}}$ and $\vartheta$ are constants. Finally, a state equation is required to describe the degree of saturation (or, alternatively, water content).

$S_{r}=F\left(\left(\sigma_{i j}-\delta_{i j} p_{a}\right),\left(p_{a}-p_{w}\right)\right)$

In Lloret and Alonso (1985), several expressions for $F$ were proposed on the basis of experimental data. The following equation describes the variation of degree of saturation with applied stress and suction:

$S_{r}=1-\left[a^{\prime}+d^{\prime}\left(\sigma-p_{a}\right)\right] \tan h\left[b^{\prime}\left(p_{a}-p_{w}\right)\right]$

where $a^{\prime}, b^{\prime}, d^{\prime}$ are constants, and $\sigma$ the relevant stress (mean or vertical for isotropic or oedometric cases).

Changes in water retention induced by external loading are small in front of changes induced by suction. In seepage problems in unsaturated soil, several relationships between water suction and moisture content have been proposed. Among them:

$S_{r}=S_{r i}+\frac{A_{w}\left(S_{r s}-S_{r i}\right)}{A_{w}+\left(C_{w}\left(p_{a}-p_{w}\right)\right)^{B_{w}}}($ Bourgeois1986)

$S_{r}=$

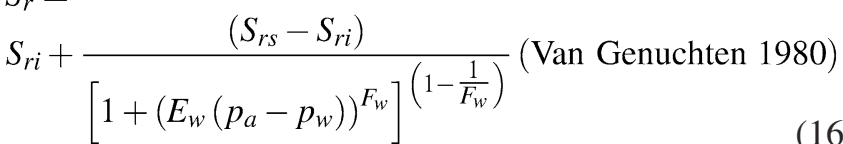

where $A_{w}, B_{w}, C_{w}, E_{w}, F_{w}, S_{r i}$ and $S_{r s}$ are constants (Van Genuchten 1980, Bourgeois 1986).

Mechanical behaviour. A practical stress-strain relationship which may take properly into account the relevant behaviour of partially saturated soils is:

$d \sigma *=D\left(d \varepsilon-d \varepsilon_{o}\right)$ 
where $\sigma^{*}$ are the net stresses:

$\sigma^{*}=\sigma-m p_{a}=\left[\begin{array}{c}\sigma_{x x}-p_{a} \\ \sigma_{y y}-p_{a} \\ \sigma_{z z}-p_{a} \\ \tau_{x y} \\ \tau_{x z} \\ \tau_{y z}\end{array}\right]$

and $m^{t}=[1,1,1,0,0,0]$.

$\varepsilon$ are the total strains:

$$
\varepsilon=\left[\begin{array}{l}
\varepsilon_{x x} \\
\varepsilon_{y y} \\
\varepsilon_{z z} \\
\gamma_{x y} \\
\gamma_{x z} \\
\gamma_{y z}
\end{array}\right]
$$

and $\varepsilon_{\mathrm{o}}$ are the volumetric strains induced by suction changes. The terms of the constitutive tangent matrix $D$ may depend on stress level and macrostructural suction. Volumetric changes induced by suction changes may be described by means of different methods. A suitable expression for computational purposes is:

$d \varepsilon_{o}=h_{s} d\left(p_{a}-p_{w}\right)$

The terms in vector $h_{s}$ will depend on macrostructural suction and stress level. Coefficients of matrix $D$ and $h_{s}$ may be defined through a constitutive model.

An approximate procedure to obtain matrix $D$ and vector $h_{s}$ is to use the concept of state surface for void ratio (Matyas and Radhakrishna 1968). This surface provides the variation of "classical" void ratio $(e)$ with applied total stress and suction for a given experimental procedure (oedometric or triaxial conditions, in most cases). For instance, for isotropic or oedometric stress conditions, the following expressions have been suggested for these state surfaces (Lloret and Alonso 1985):

$$
\begin{aligned}
e=\frac{n}{1-n}= & d+a\left(\sigma-p_{a}\right)+b\left(p_{a}-p_{w}\right) \\
& +c\left(\sigma-p_{a}\right)\left(p_{a}-p_{w}\right) \\
e=\frac{n}{1-n}= & d+a \log \left(\sigma-p_{a}\right)+b \log \left(p_{a}-p_{w}+p_{a t}\right) \\
& +c \log \left(\sigma-p_{a}\right) \log \left(p_{a}-p_{w}+p_{a t}\right)
\end{aligned}
$$

where $a, b, c$ and $d$ are constants, and $\sigma$ is the relevant stress which defines the stress state. The state surface given by Eqs. (21) or (22) does not consider explicitly the influence of deviatoric stresses on volumetric change induced by suction changes.

Coefficients of matrix $D$ may be defined through a non-linear elastic model. The tangent compressibility modulus $K_{t}$ is (for isotropic test conditions) obtained from Eqs. (21) or (22). The shear modulus $\left(G_{t}\right)$ can be obtained assuming a constant Poisson's ratio $v$ (model 1$)$ or from a hyperbolic shear stress-shear strain law (model 2).
$\frac{1}{K_{t}}=\frac{d \varepsilon_{v}}{d\left(\sigma-p_{a}\right)}=\frac{1}{1+e_{0}} \frac{d e}{d\left(\sigma-p_{a}\right)}$

$G_{t}=\frac{3 K_{t}(1-2 v)}{2(1-v)}$

$G_{t}=\left[G_{0}+M\left(p_{a}-p_{w}\right)\right]\left[1-\frac{\left(\sigma_{1}-\sigma_{3}\right) R_{f}}{\left(\sigma_{1}-\sigma_{3}\right)_{f}}\right]^{2}$

$G_{0}$ and $R_{f}$ are parameters of the hyperbolic model (Duncan and Chang 1970). $\left(\sigma_{1}-\sigma_{3}\right)$ is the deviatoric stress, and $\left(\sigma_{1}-\sigma_{3}\right)_{f}$ is the deviatoric stress at failure. Note that the stiffening effect of suction increase has been introduced in Eq. (25), through the initial $G$ modulus, by means of a linear relationship with parameter $M$. This is in accordance with some experimental evidence (Brull 1980).

The effect of suction on shear strength is taken into account via an extended Mohr-Coulomb criterion (Fredlund et al. 1978; Gens 1993) for a planar failure envelope:

$$
\begin{aligned}
& \tau_{f}=c+\left(\sigma_{n}-p_{a}\right) \tan \phi^{\prime} \\
& c=c^{\prime}+\left(p_{a}-p_{w}\right) \tan \phi^{b}
\end{aligned}
$$

where $\tau_{f}$ is the shear stress at failure, $\sigma_{n}$ the total normal stress acting on the failure plane, $c^{\prime}$ the effective cohesion, $\varphi^{\prime}$ the effective internal friction angle, $c$ the apparent cohesion, and $\varphi^{b}$ the apparent friction angle to account for the increase of strength with suction. However, as pointed out by Escario and Sáez (1986), the angle $\varphi^{b}$ should be a function of suction. In particular, $\varphi^{b} \rightarrow \varphi^{\prime}$ as $s \rightarrow 0$ to ensure consistency with the saturated strength envelope. $\varphi^{b}$ was made dependent on suction, as explained in the text.

\section{References}

Alonso EE (2000) General report: cuttings and natural slopes. In: Evangelista A, Picarelli L (eds) The geotechnics of hard soilssoft rocks. Balkema, Rotterdam, vol 3, pp 1557-1588

Alonso EE, Batlle F, Gens A, Lloret A (1988) Consolidation analysis of partially saturated soils - Application to earthdams construction. In: Swoboda G (ed) Numerical methods in geomechanics. Balkema, Rotterdam, pp 1303-1308

Baldelli A, Burghignoli A, Gens A, Muir Wood DM, Scarpelli G, Smith IM (1992) Physical processes in the Mediterranean climates and related slope instabilities in overconsolidated clayey soils. Project EPOCH. European Programme on Climatology and Natural Hazard 1st Progr Rep. Commission European Communities, Brussels

Baldelli A, Burghignoli A, Gens A, Muir Wood DM, Scarpelli G, Smith IM (1994) Physical processes in the Mediterranean climates and related slope instabilities in overconsolidated clayey soils. Project EPOCH. European Programme on Climatology and Natural Hazard Final Rep. Commission European Communities, Brussels

Bjerrum L (1967) Progressive failure in slopes of overconsolidated plastic clay and clay shales. J Soil Mech Found Div ASCE 93(SM5):3-49

Bourgeois M (1986) Le concept de barrière capillaire. Etude par modèle numérique. Thèse, CGI, Ecole Mines Paris, 133 pp 
Bromhead EN (2000) Panel report: lessons from the Selborne slope stability experiment. In: Evangelista A, Picarelli L (eds) The geotechnics of hard soils-soft rocks. Balkema, Rotterdam, vol 3, pp 1441-1481

Brull A (1980) Caractéristiques mécaniques des sols de fondation de chaussés en fonction de leur état d'humidité et de compacité. Coll Int Compactage 1:113-118

Brun P (1989) Cinétique d'infiltration au sein d'une couche d'argile compactée. Étude expérimentale et numérique. $\mathrm{PhD}$ Thesis, ENSMP, Paris, 219 pp

Cancelli A, Chinaglia N (1993) Shear strength parameters and slope stability in argillaceous rocks. In: Anagnastopoulos A, Schlosser F, Kalteziotis N, Frank R (eds) Geotechnical engineering of hard soils-soft rocks. Balkema, Rotterdam, vol 2, pp 1087-1092

Chandler RJ (1984) Recent European experience of landslides in over-consolidated clays and soft rocks. In: Proc 4th Int Symp Landslides, 16-21 September, Toronto. Can Geotech Soc, vol 1, pp 61-81

Cooper MR (1996) The progressive development of a failure slip surface in over-consolidated clay at Selborne, UK. In: Senneset K (ed) Landslides. Balkema, Rotterdam, vol 2, pp 683-687

D'Elia B, Picarelli L, Leroueil S, Vaunat J (1998) Geotechnical characterization of slope movements in structurally complex clay soils and stiff jointed clays. Riv Ital Geotec 3/98:5-47

DiMaio C (1996) The influence of pore fluid composition on the residual shear strength of some natural clayey soils. In: Senneset K (ed) Landslides. Balkema, Rotterdam, vol 2, pp 1189-1194

Duncan JM, Chang CY (1970) Non-linear analysis of stress and strain in soils. J Soil Mech Found Div ASCE 96:1629-1653

Escario V, Sáez J (1986) The shear strength of partly saturated soils. Géotechnique 36:453-456

Franchini E, Callari I (1988) Campagna di Lettura Strumentale lungo il versante Posatora, Fornetto, ex Ospedale Psichiatrico. Comune di Ancona, Italia

Fredlund DG, Rahardjo H (1993) Soil mechanics for unsaturated soils. Wiley, New York

Fredlund DG, Morgenstern NR, Widger RA (1978) The shear strength of unsaturated soils. Can Geotech J 15:313-321

Frydman S, Shvarzman A, Talesnick M (1996) Residual strength of Israeli cohesive soils. In: Senneset K (ed) Landslides. Balkema, Rotterdam, vol 2, pp 1225-1230

Gens A (1993) Shear strength. Unsaturated soils: recent developments and applications. Civil Engineering European Courses. Programme of Continuing Education. Universidad Politécnica de Catalunya, Barcelona
Irmay S (1954) On the hydraulic conductivity of unsaturated soils Trans Am Geophys Union 35:463-468

Jacquard C (1988) Etude expérimentale d'une barrière capillaire avec un modèle de laboratoire. PhD Thesis, CGI, Ecole Mines Paris, $165 \mathrm{pp}$

Kavvadas MJ (2000) General report: modelling the soil behaviour. Selection of soil parameters. In: Evangelista A, Picarelli L (eds) The geotechnics of hard soils-soft rocks. Balkema, Rotterdam, vol 3, pp 1441-1481

Lambe TW, Whitman RV (1968) Soil mechanics. Wiley, New York

Leroueil S (2001) 39th Rankine lecture: natural slopes and cuts: movement and failure mechanisms. Géotechnique 51(3): 197-243

Lloret A, Alonso EE (1980) Consolidation of unsaturated soils including swelling and collapse behaviour. Géotechnique 30(4): 449-477

Lloret A, Alonso EE (1985) State surfaces for partially saturated soils. In: Proc 11th Int Conf Soil Mechanics and Foundation Engineering, 12-16 August, San Francisco. Balkema, Rotterdam, vol 2, pp 557-562

Matyas EL, Radhakrishna HS (1968) Volume change characteristics of partially saturated soils. Géotechnique 18(4):432-448

Olivella S, Carrera J, Gens A, Alonso EE (1994) Non-isothermal multiphase flow of brine and gas through saline media. Transport Porous Media 15:271-293

Olivella S, Gens A, Alonso EE, Carrera J (1996) Numerical formulation for a simulator (CODE-BRIGHT) for the coupled analysis of saline media. Eng Comput 13(7):87-112

Potts DM, Kovacevic N, Vaughan PR (1997) Delayed collapse of cut slopes in stiff clay. Géotechnique 47(5):953-982

Richards LA (1931) Capillary conduction of liquids through porous mediums. Physics 1:318-333

Sibley JW, Williams DJ (1990) A new filter material for measuring soil suction. Geotech Test J 13(4):381-384

Skempton AW (1964) Long term stability of clay slopes. Géotechnique 14:77-101

Van Genuchten MT (1980) A closed-form equation for predicting the hydraulic conductivity of unsaturated soils. Soil Sci Am J 49(5):892-898

Vaughan PR, Walbancke HJ (1973) Pre pressure changes and the delayed failure of cutting slopes in over-consolidated clay. Géotechnique 23:531-539

Yoshimi Y, Osterberg JO (1964) Compression of partially saturated cohesive soils. J Soil Mech Found Div ASCE 89(SM4): $1-24$ 